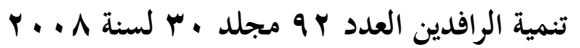

$$
\begin{aligned}
& \text { كلية الإدارة والاقتصاد -جامعة الموصل } \\
& \text { ص ص[11..-91] } \\
& \text { الخصخصة كخيار في القطاع المصرفي العراقي المصاصي } \\
& \text { زهراء أحمد محمد توفيق النعيمي } \\
& \text { مدرس مساعد -قسم العلوم المالية والمصرفية } \\
& \text { كلية الادارة والإقتصاد - جامعة الموصل }
\end{aligned}
$$

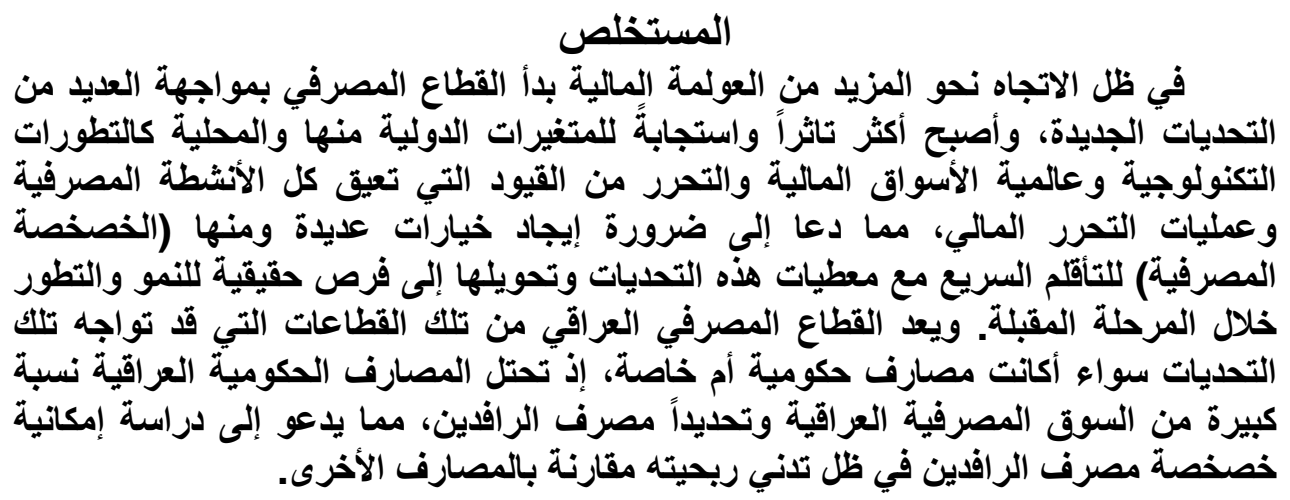

\title{
Privatization is an Option to the I raqi Banking Sector through Modern Banking Trends
}

\author{
Zahraa A. M. T. AL-Noai'mee \\ Assistant Lecturer \\ Department of Financial and Banking \\ University of Mosul
}

\begin{abstract}
Throughout the trend towards more financial globalization, the banking sector faced a number of new challenges, and it become more affected and more respondent to the international and national changes, such as technical developments, internationality of financial markets. The freeing of constraints precludes all the banking activities; so, financial freeing call for the necessity to find several options including (Banking privatization) to the rapid adjustment with the inputs of these challenges and convert them into true opportunities for growth and development during the future stage. The Iraqi banking sector is regarded as one of the sectors that face these challenges either a governmental or private banks. The Iraqi governmental banks form a large proportion in Iraqi
\end{abstract}

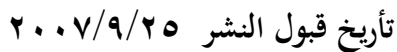

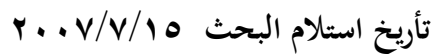


banking market, specifically; AL - Rafidain Bank and that may call for studying the possibility of this bank privatization under its low profitability compared with other banks.

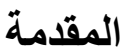

يحتل القطـاع المصرفي مركز اً حيويـاً في إقتصاديات الدول المتقدمـة منهـا

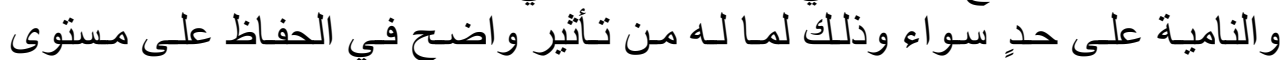

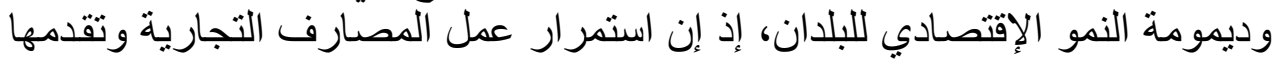

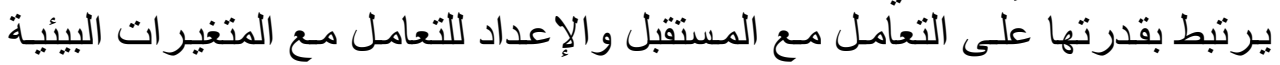
كافة.

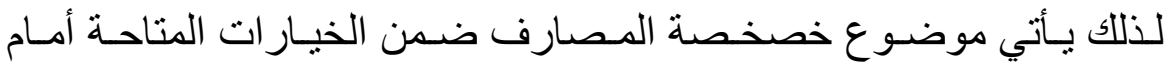

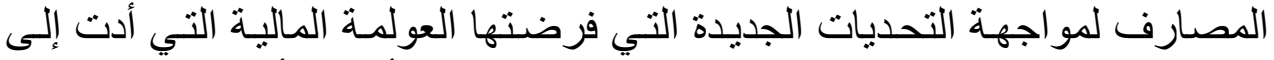

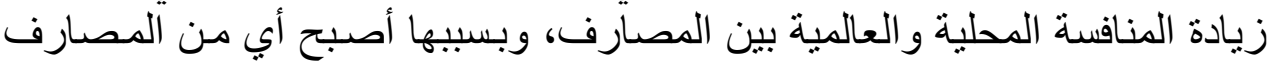

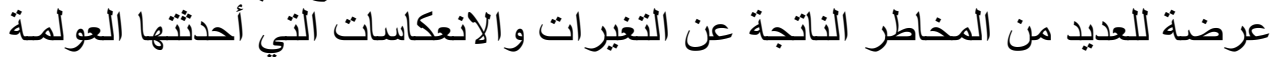

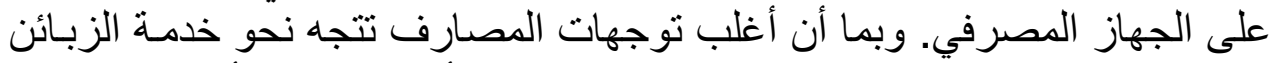

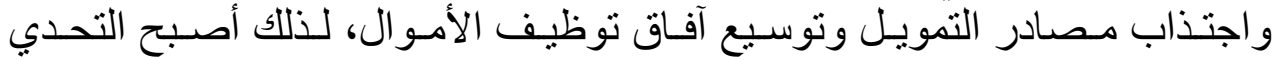

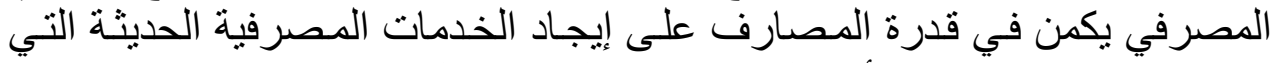

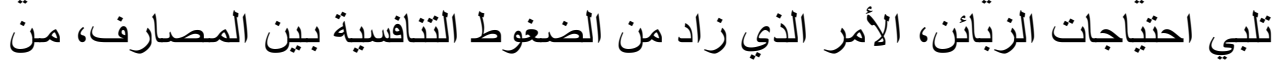

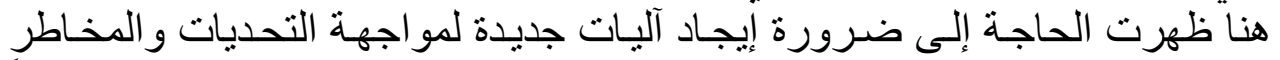

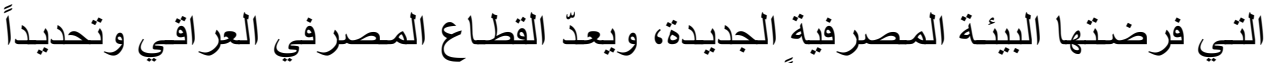

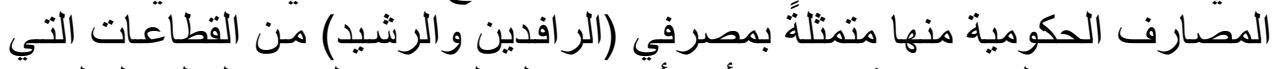
قد تو اجه خيار الخصخصة بوصفه أحد أهم عو امل التحرر والتوجه التها المالي العالمي.

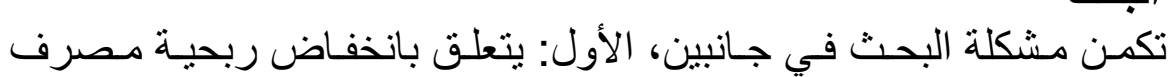

\section{مشكلة البحث}

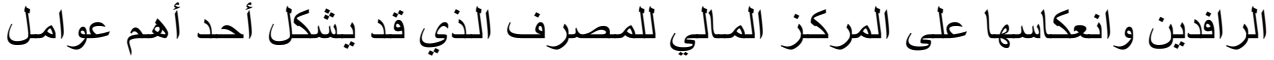

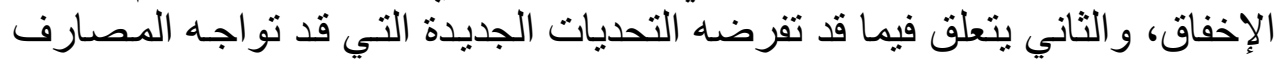

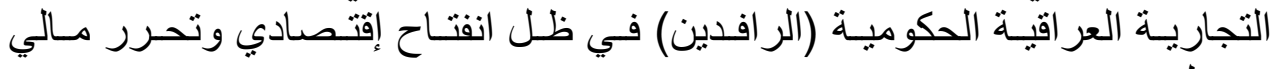
محتمل. - n

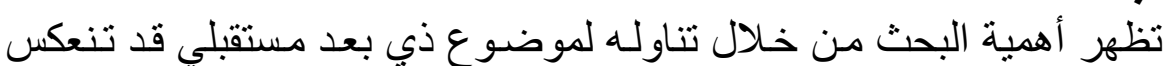

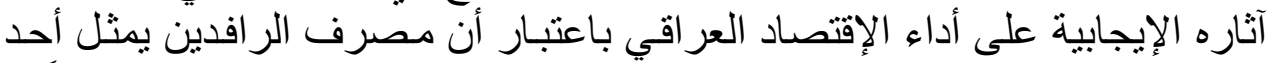

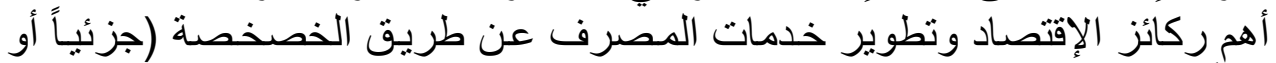

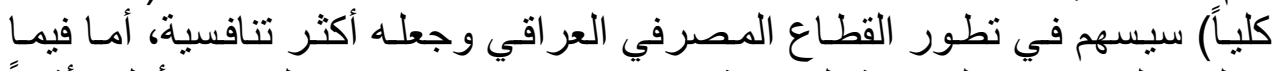

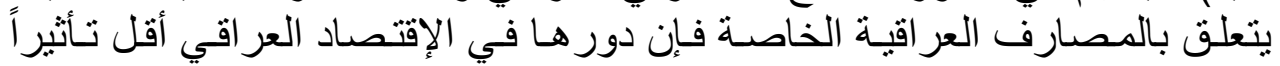
وذللك لصغر حجمها من حيث (الموجودات، رأس المال، الودائع). 


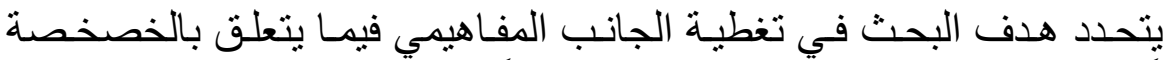

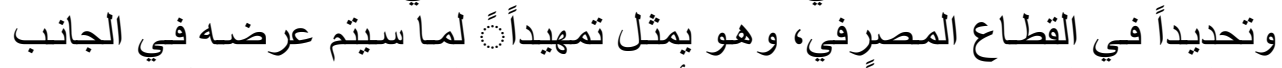

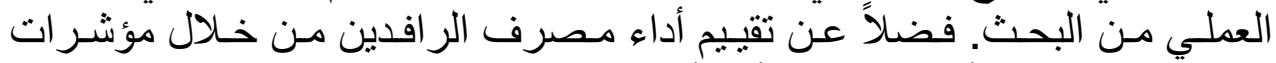

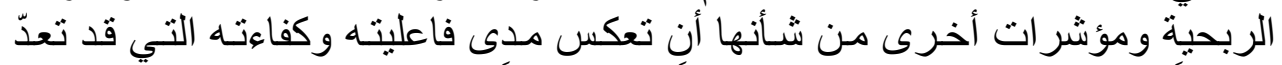

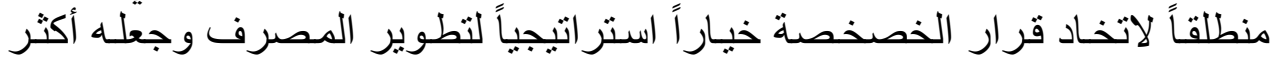
قدرة على مو اجهة تحديات العولمة المالية.

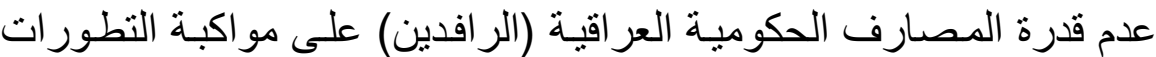
فرضية البحث

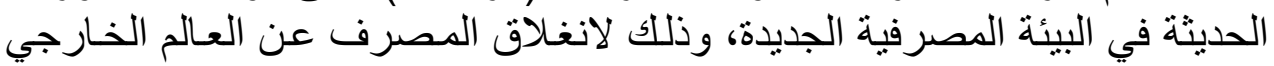

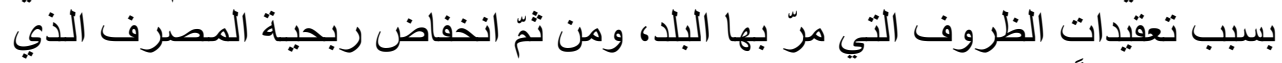

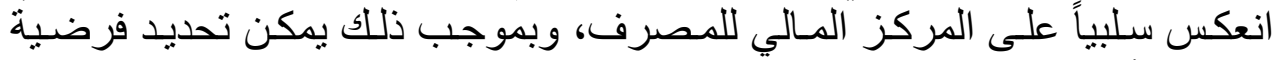

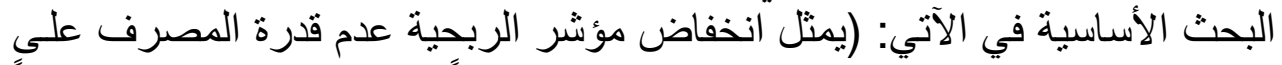

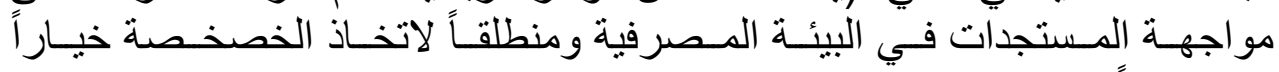
(ستر اتيجياً).

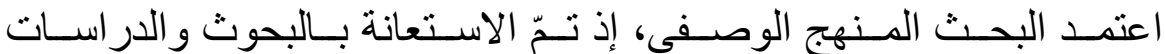

منهج البحث

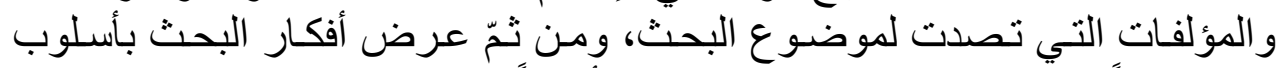

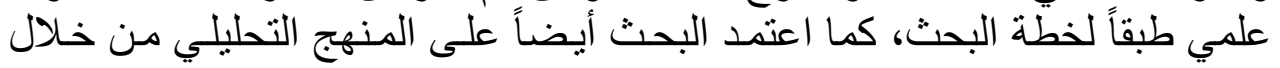

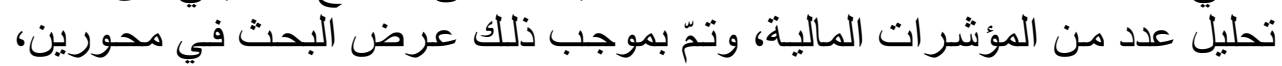

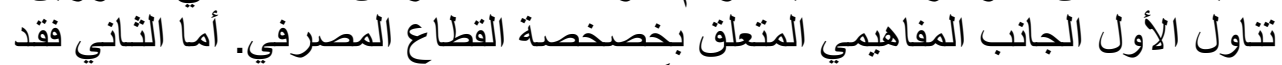

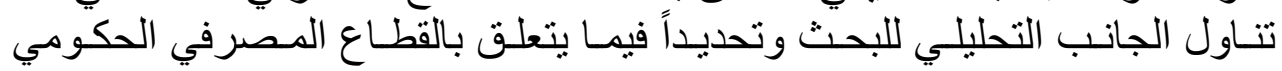

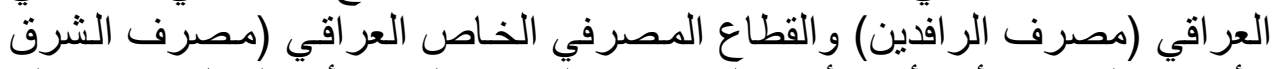

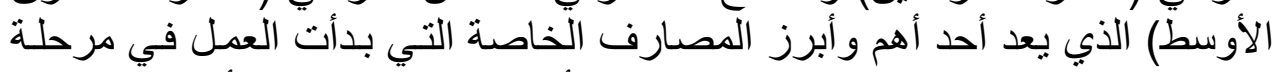

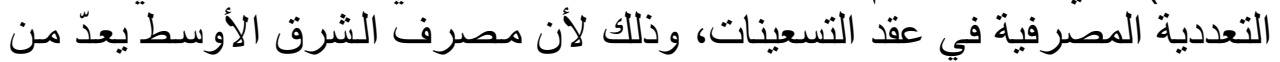

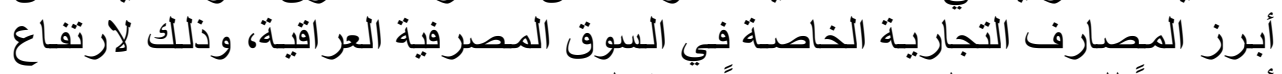
أدائه وفقاً للعديد من المؤشر ات قياساً ببقية المصارف الفوف.

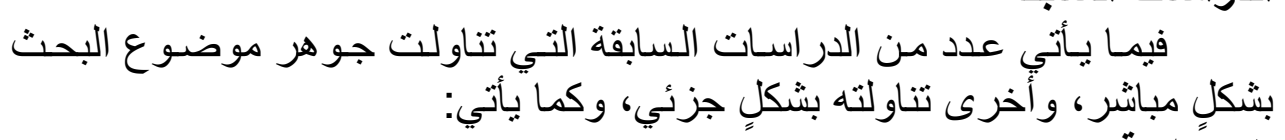

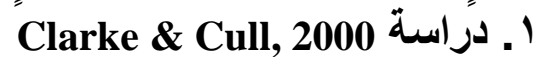

بحثت هذه الدراسة خصخصة المصارف في الأرجنتين، وقد توصلت إلى أن أن

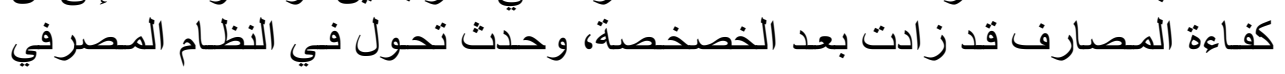


الأرجنتيني وزاد من تطوره بشكلٍ كبير ممـا انعكس في تقليل أهميـة المصارف

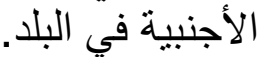

Crystal, Dayes \& Goldbery, 2001 . دراسة

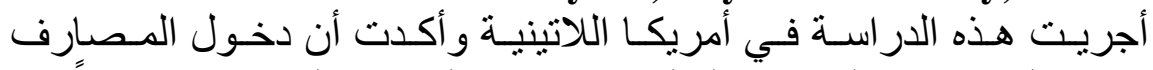

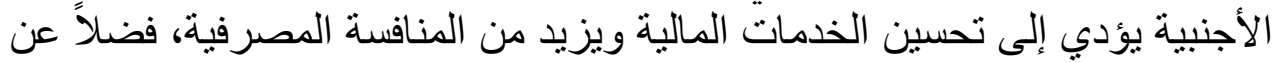
أنها تسهل من سر عة خصخصة المصارف المكات المحلية المملوكة للاولة.

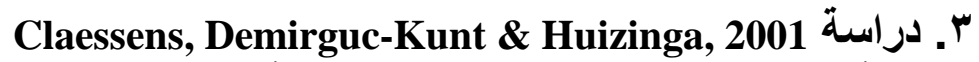

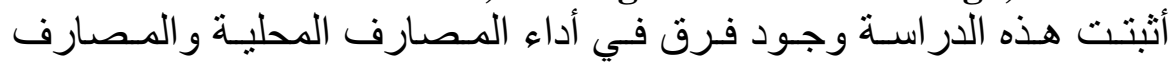

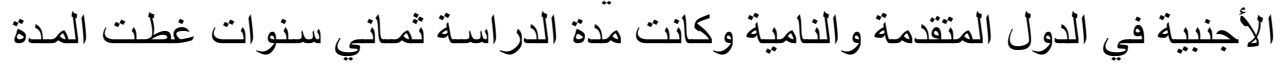

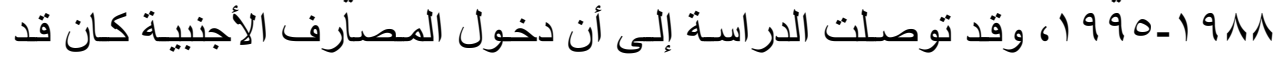

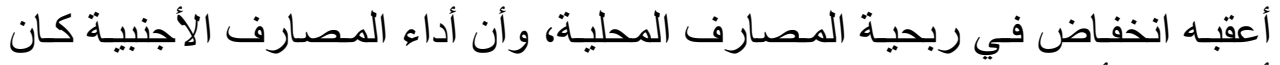
أفضل من أداء المصارف الميله المحلية.

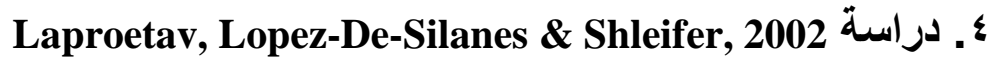

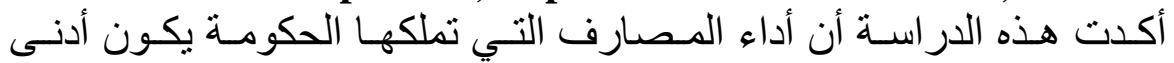
مقارنةً بأداء مصارف القطاع الخاص.

Fries \& Taci, 2003 ـ دراسة

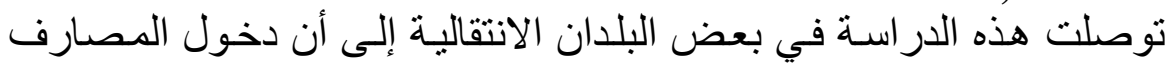

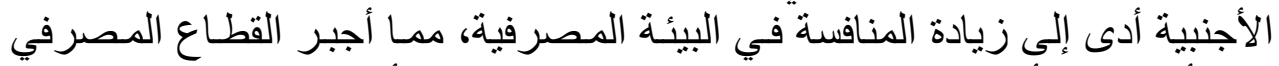

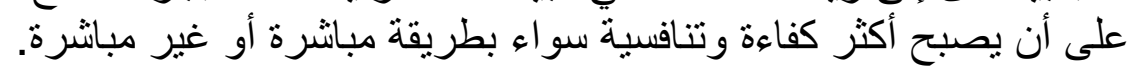

T. 7 دراسة

بحثت هذه الدراسـة في أداء الدصارف في أحد عشر بلداً انتقالياً، وأكدت

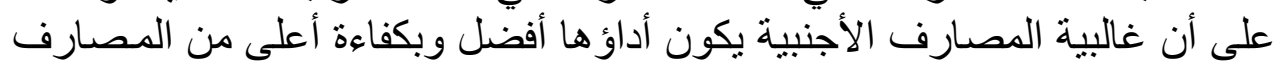

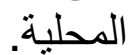

\section{الخصخصة المصرفية: مفهومها وأساليبها ودوافعها

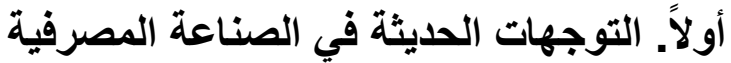

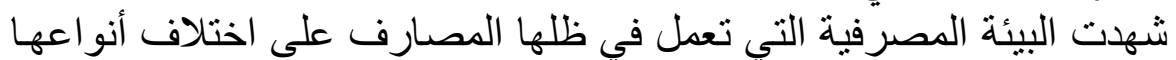

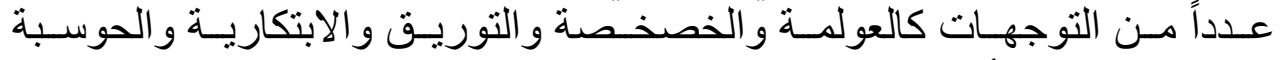

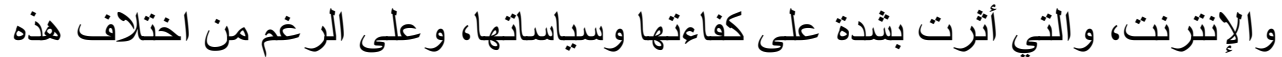

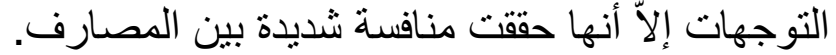

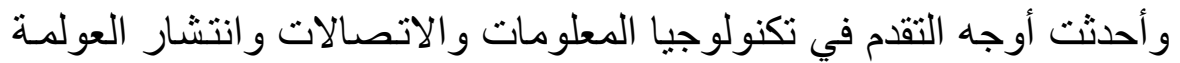

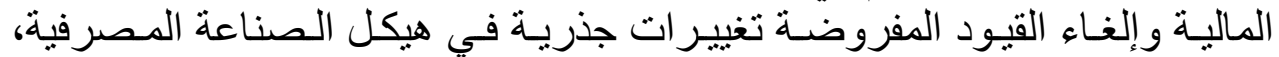


فالابتكار في الأدوات المالية وتز ايد المنافسة أدى إلى تخفيض هو امش في الأنشطة

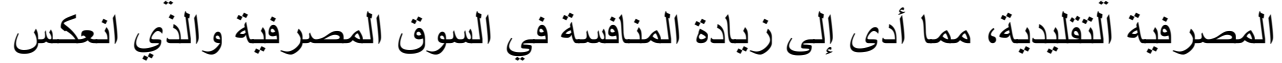

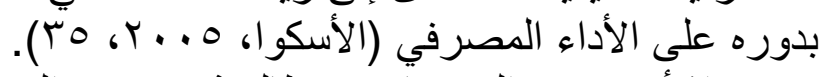

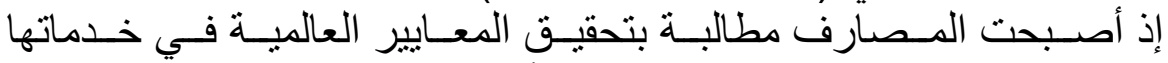

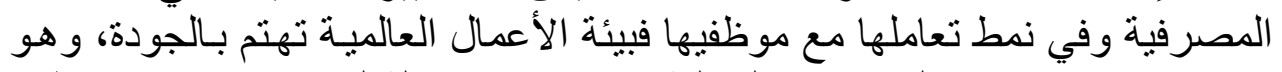

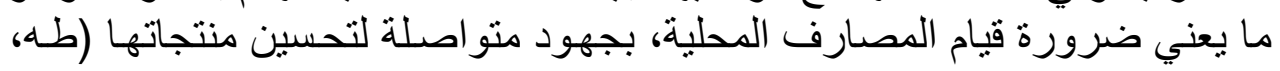

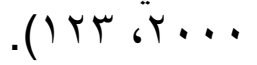

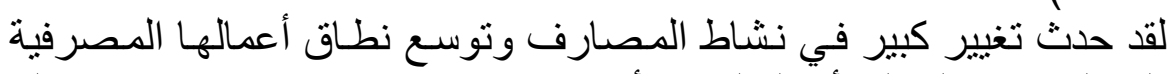

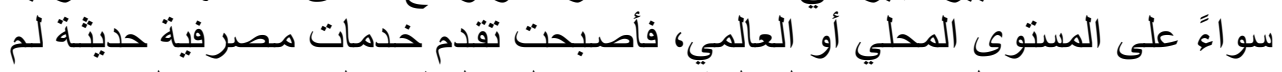

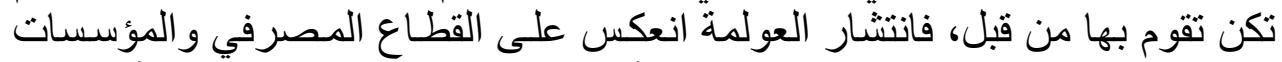

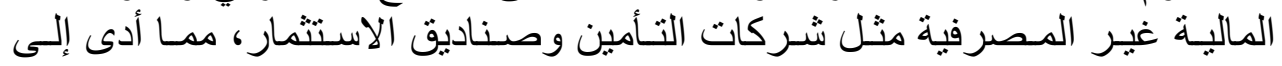

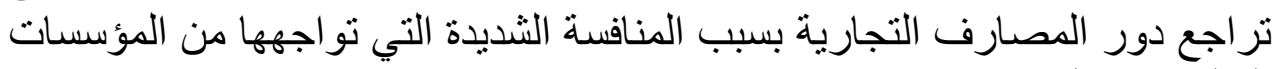

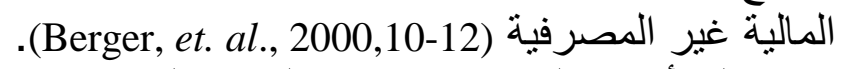

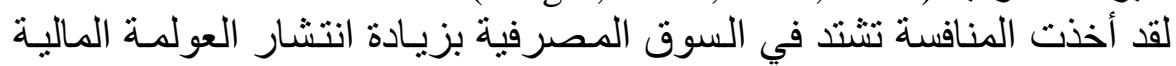

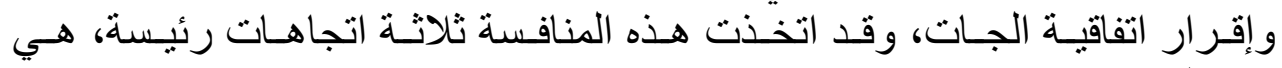

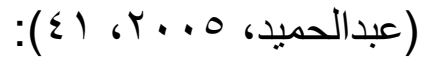

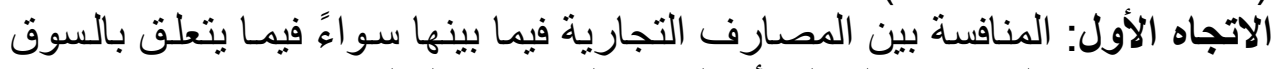
المصرفية المحلية أو السوق المصنية الهصرفية العالمية.

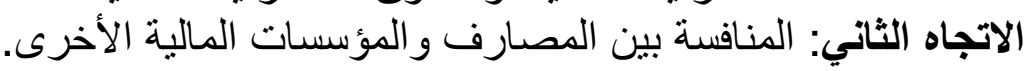

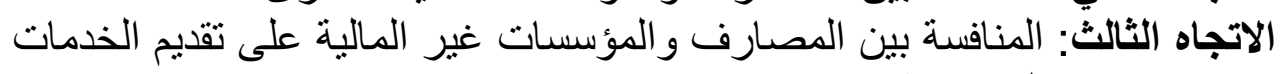
المصرفية.

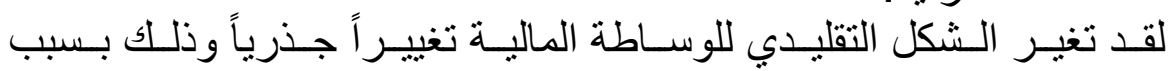

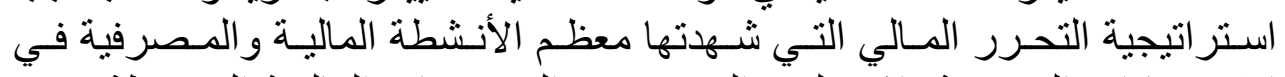

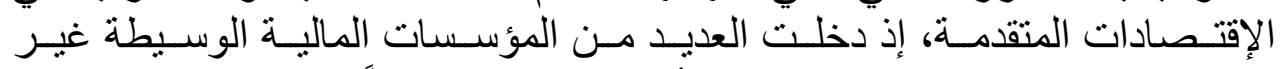

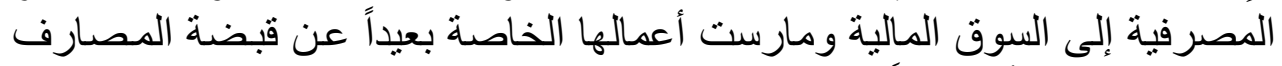

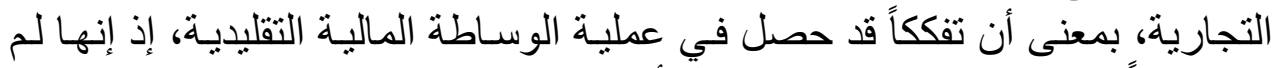

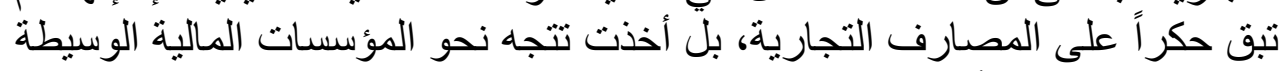

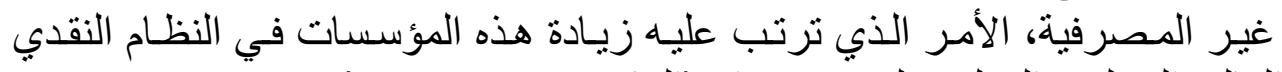

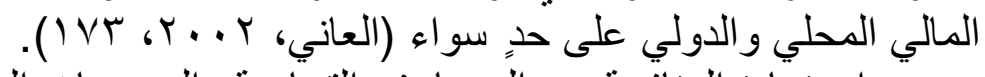

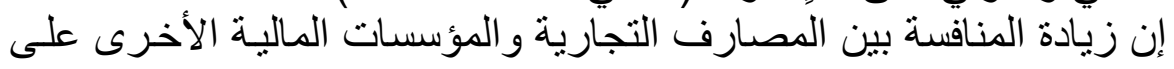

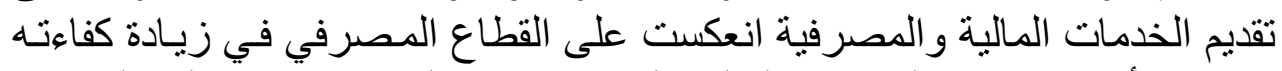

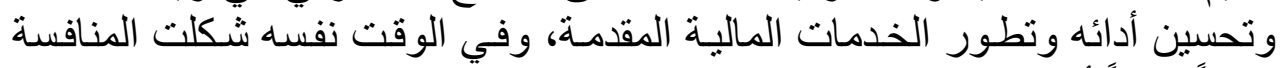
تحدياً كبير اً أمام المصارف الطور الصغيرة (Fries et.al., 2002, 52-73). وفي ظل هذه المنافسة الثديدة فرضت تحديرة بالآتي : 


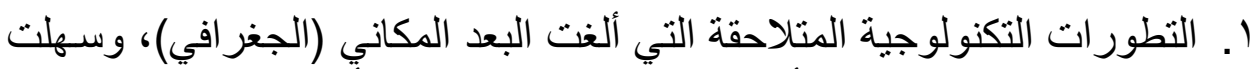

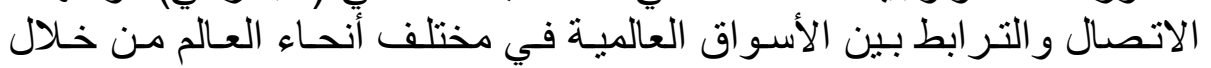

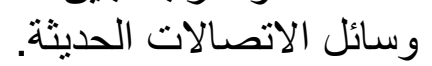

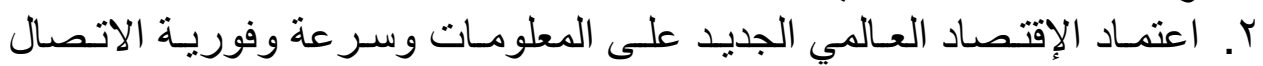

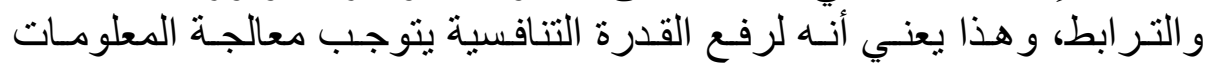

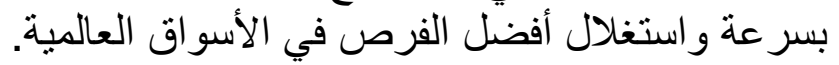

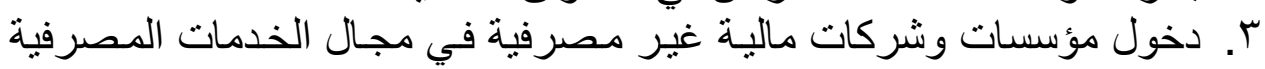

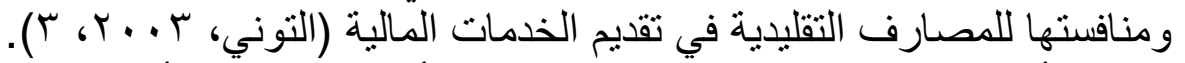

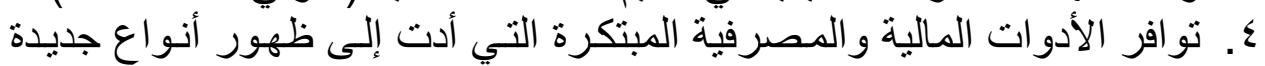

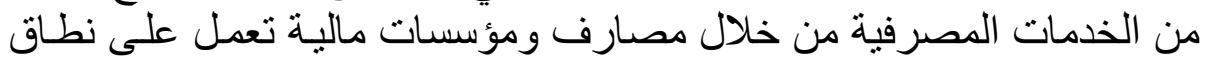
السوق العالمية (Hasan \& Marton, 2003, 15). ○. الاتجاه نحو توحيد مختلف الأعمال المصرفية والخدمات المالية وحتى خدمات

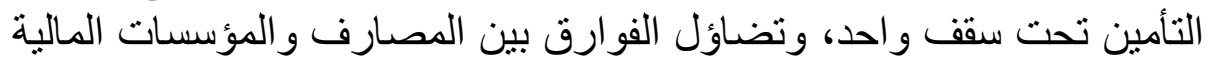

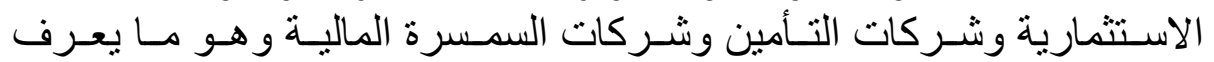
باستر اتيجية المصرف التئن الثامل.

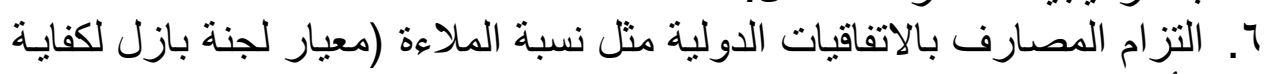

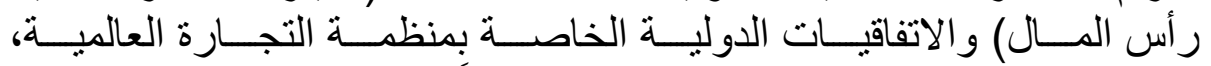

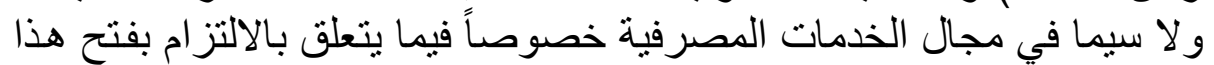

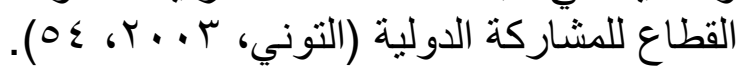

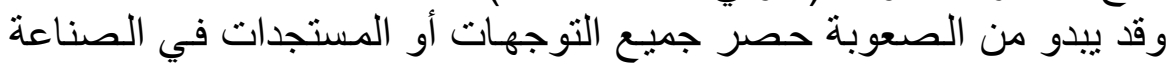

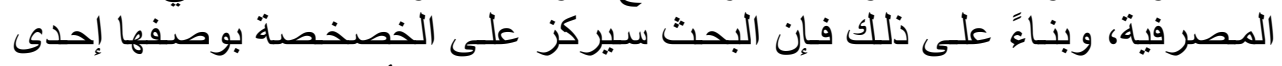
التوجهات الحديثة وركيزة من ركائز التحرر المالي سواء أكان ذلك للـئه للدول المتقدمـة أم النامية.

ثانياً. الخصخصة المصرفية

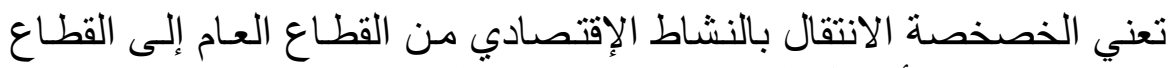

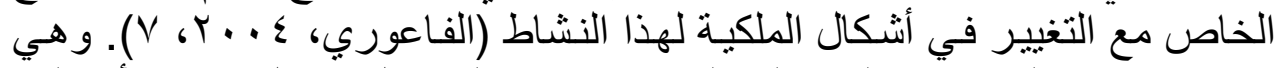

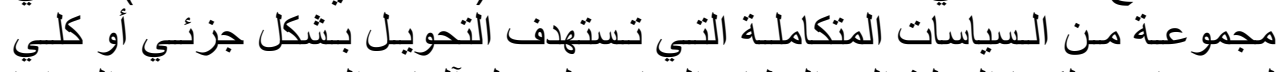

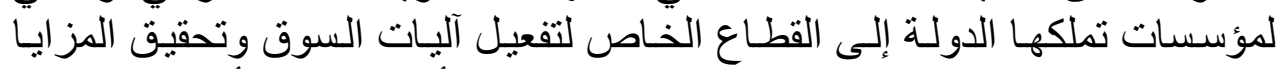

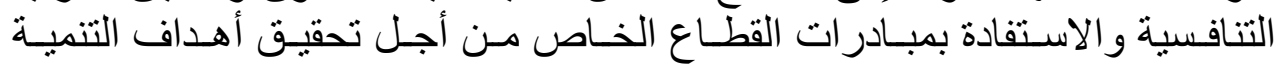

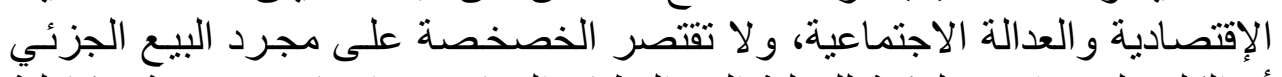

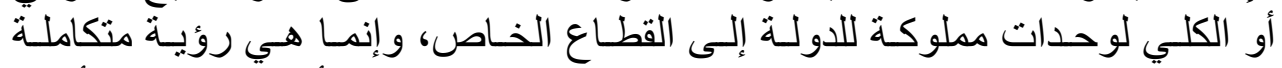

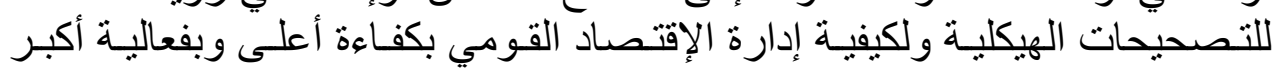

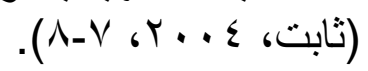

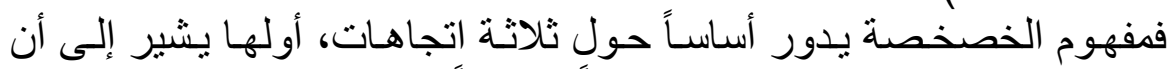

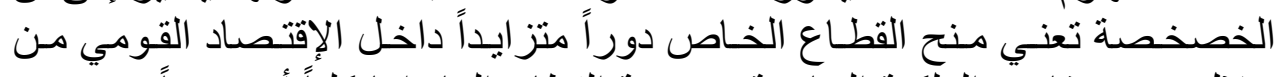

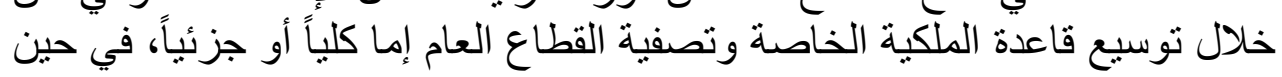




\section{[9v] [ النعيمي}

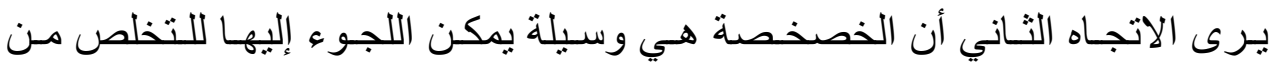

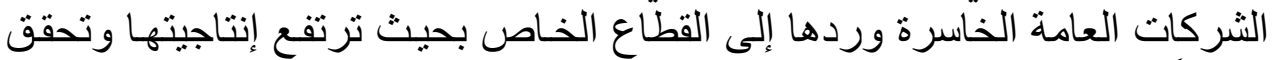

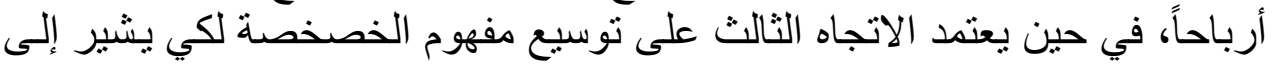

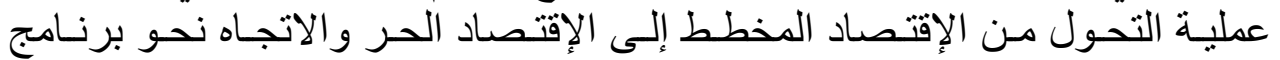

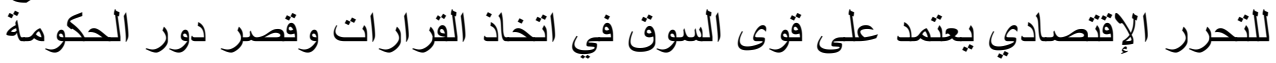

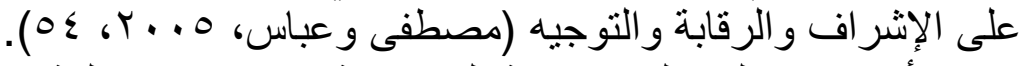

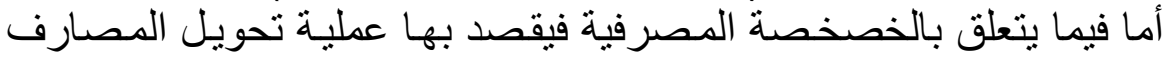

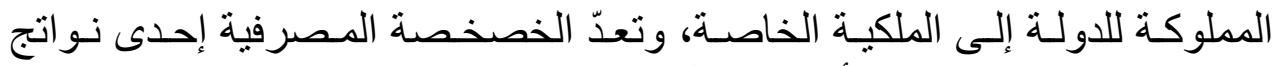

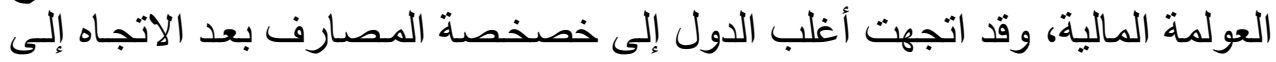

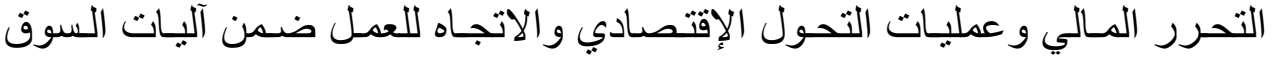
. ( ) ( )

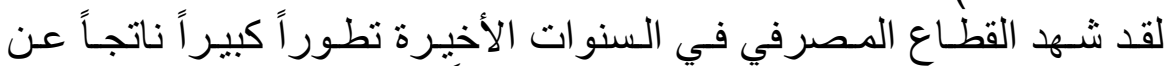

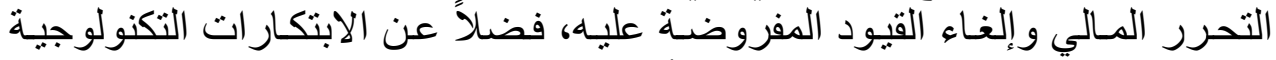

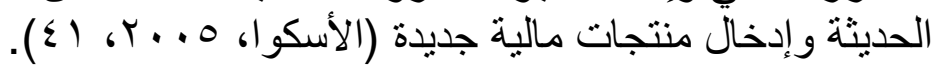

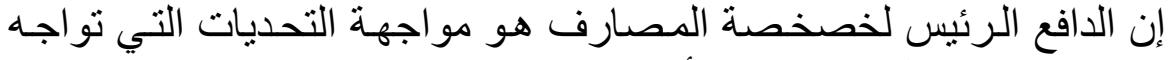

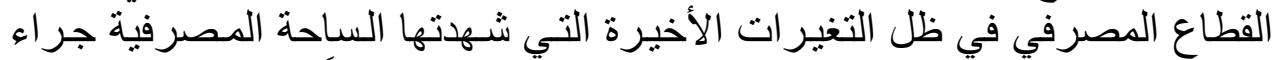

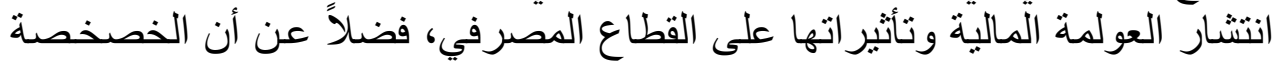

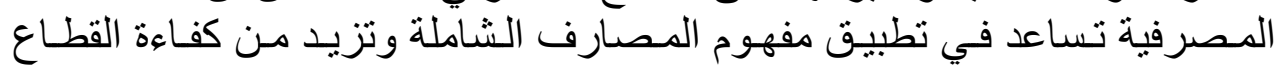

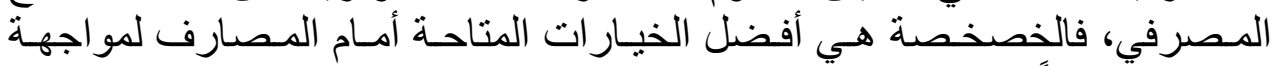

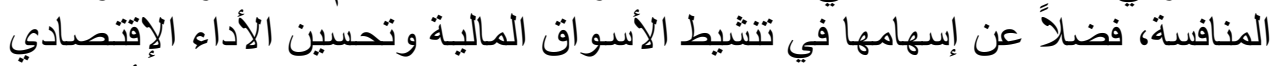

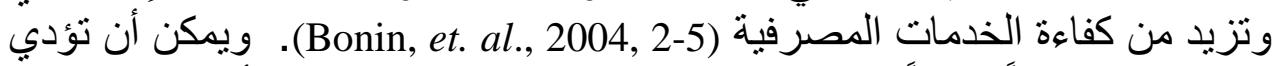

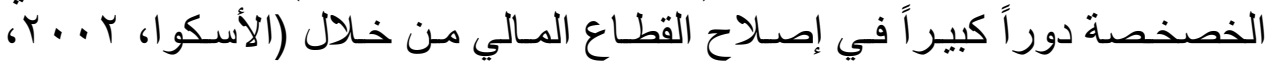
$:(r)$

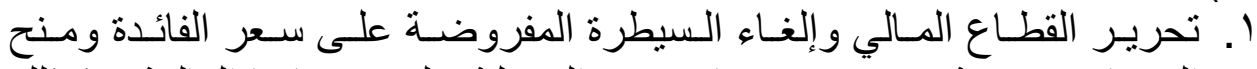

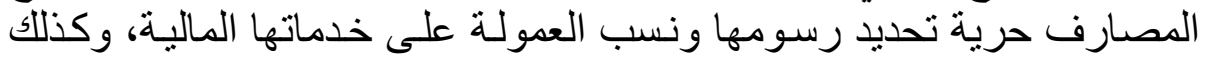

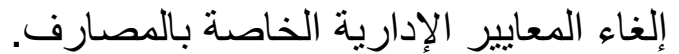

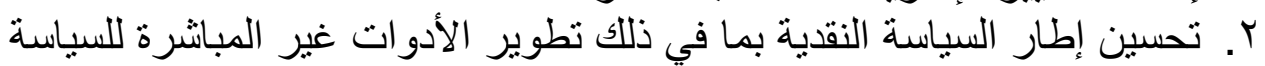
النقدية. r. تحربر التجارة في الخدمات الماليـة بما في ذلك رفع القيود عن الاستثمار ات

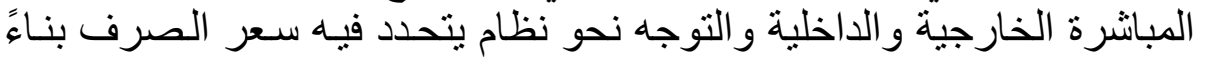
على السوق. ع. تقوية النظم الاحترازية والإطار الإشر افي بما في ذلك إعادة رسملة المصارف وتعزيز الإفصاح و الثفافية.

ثالثاً. أساليب الخصخصة 


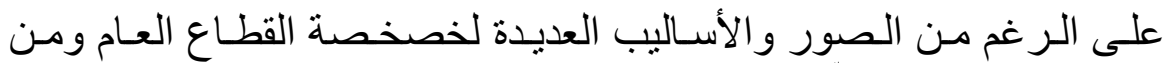

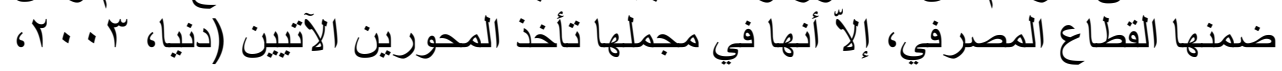

ا ـ خصخصة الملكيـة: وتعنـي تحويـل ملكيـة المشروع كليـاً أو جزئيـاً إلى ملكيـة

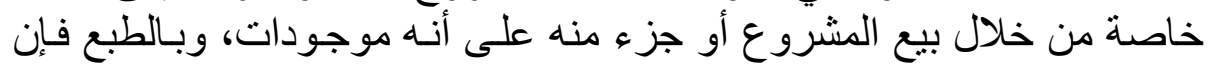

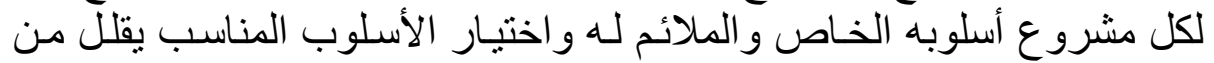

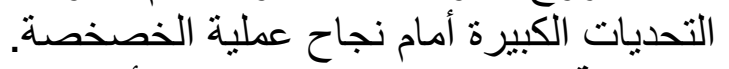

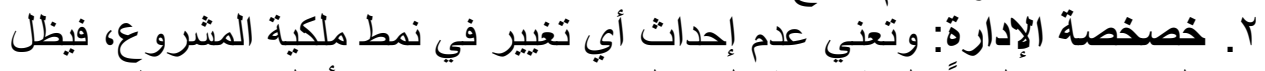

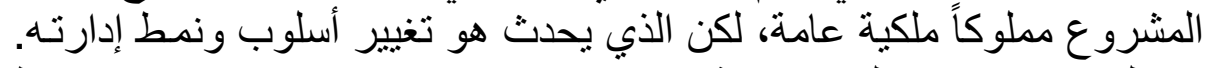

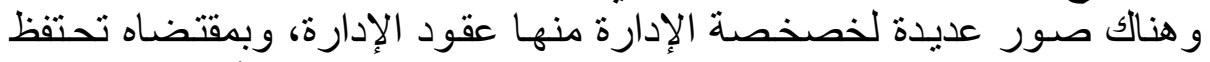

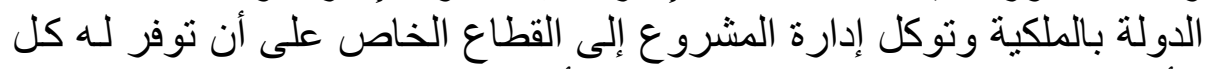

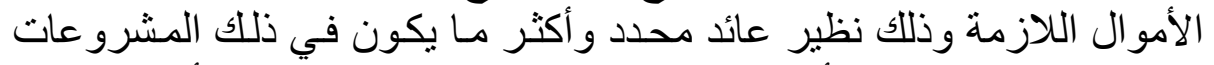

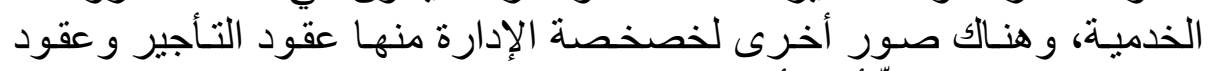

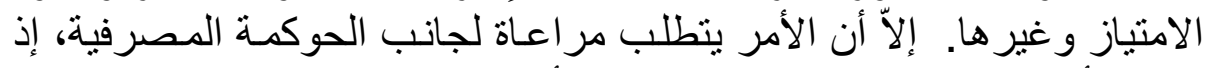

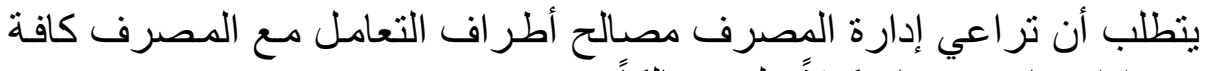
عند إدارتها بوصنفا أنسا وكيلاً وليس مالكاً.

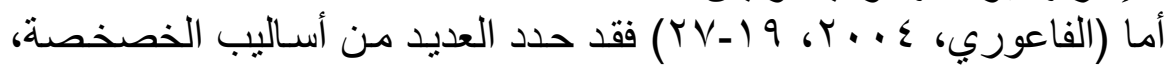

$$
\begin{aligned}
& \text { وهي: } \\
& \text { • عقود الإدارة. } \\
& \text { عقود التأجير . عقود الادو. } \\
& \text { أسلوب الامتياز. } \\
& \text { البيع إلى القطاع الخاص. } \\
& \text { مقايضة الديون. }
\end{aligned}
$$

تجزئة المشروع أو إعادة الهيكلة و العمل بالأسس التجارية

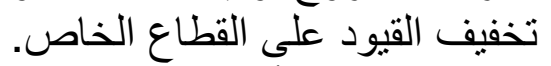

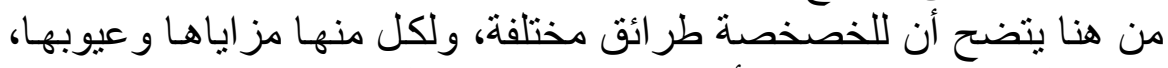

\begin{tabular}{|c|c|c|c|c|}
\hline أسباب الاختيار & الأهداف & السلبيات & (الإيجابيات) & الأسلوب \\
\hline 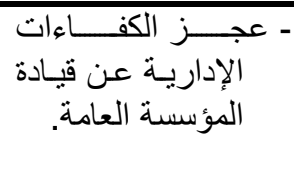 & 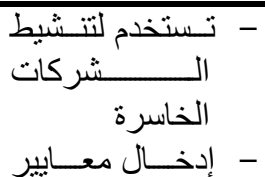 & 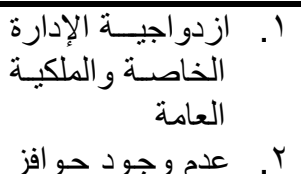 & 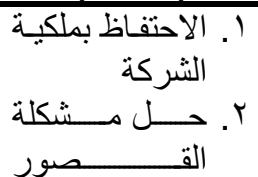 & عقد الإدارة \\
\hline
\end{tabular}

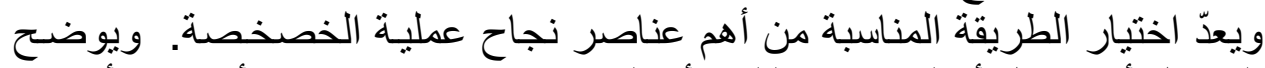

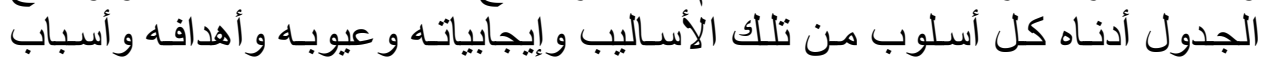

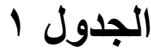

أساليب الخصخصة، إيجابياتها، سليباتها، أهدافها، سبب الاختيار 


\section{النعيمي [99]}

\begin{tabular}{|c|c|c|c|c|}
\hline أسباب الاختيار & الأهداف & السلبيات & (الإيجزابيات) & الأسلوب \\
\hline & 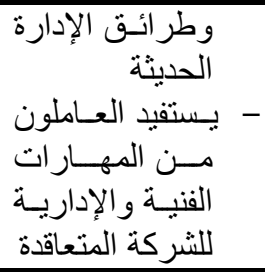 & 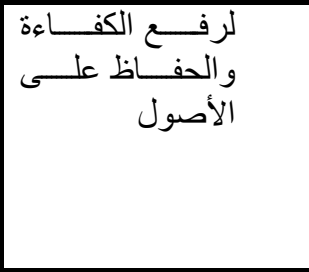 & الإداري & \\
\hline 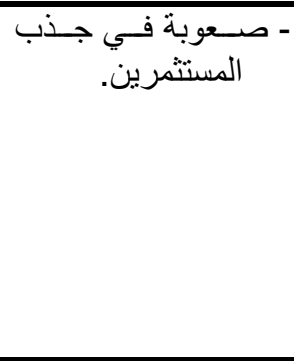 & 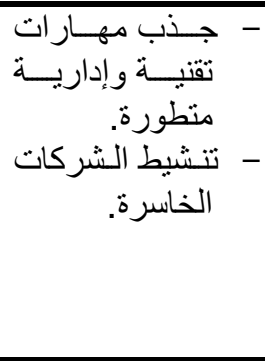 & 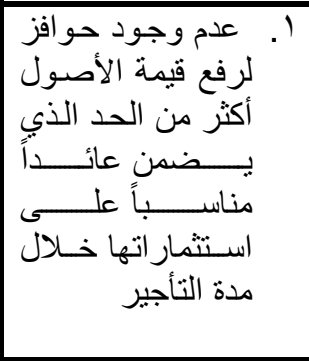 & 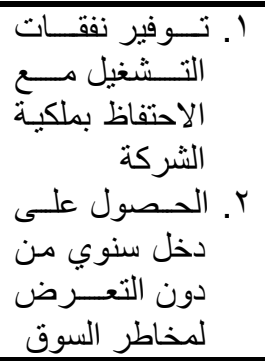 & عقود التأجير \\
\hline 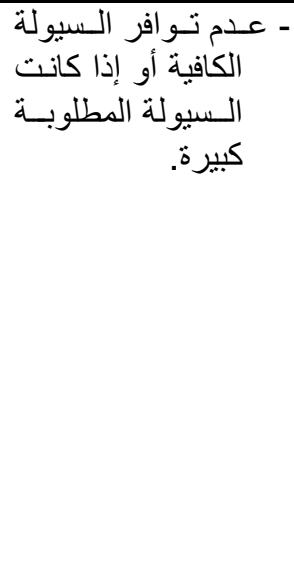 & 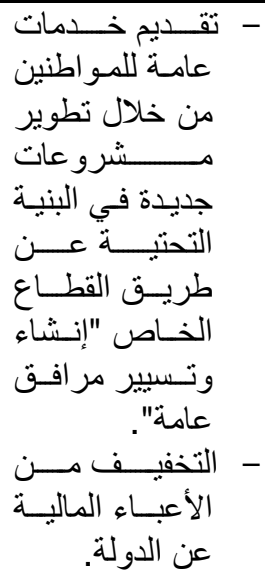 & 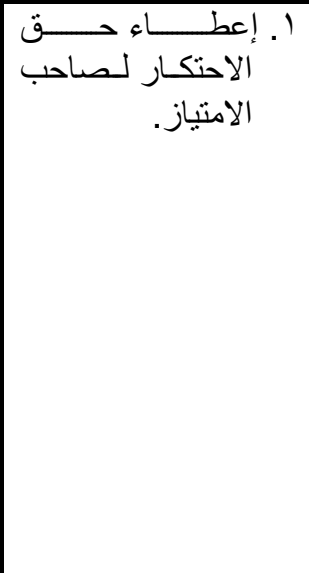 & 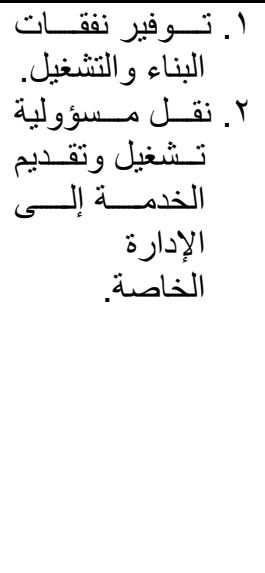 & $\begin{array}{c}\text { منح الامتياز } \\
\text { Build- } \\
\text { Operation } \\
\text { Owned } \\
\text { Build- } \\
\text { Operation } \\
\text { Transfer }\end{array}$ \\
\hline 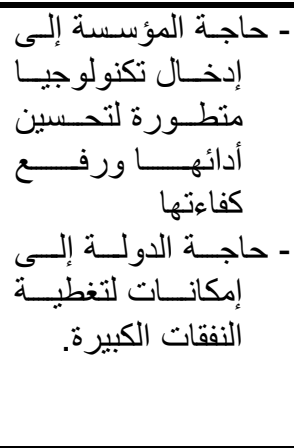 & 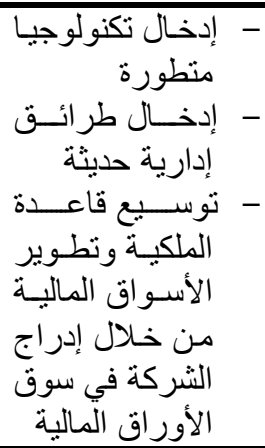 & 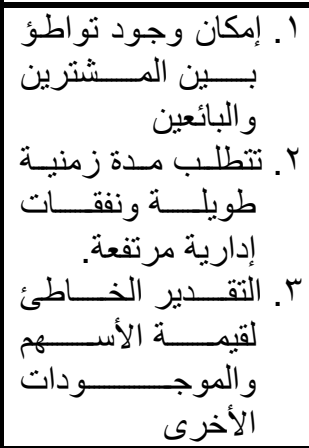 & 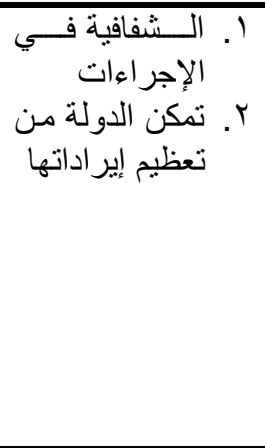 & 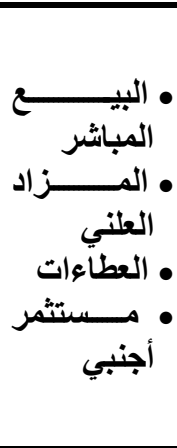 \\
\hline 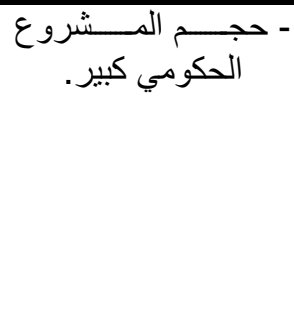 & 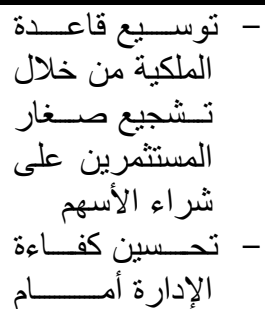 & 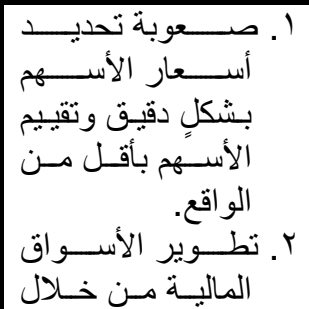 & 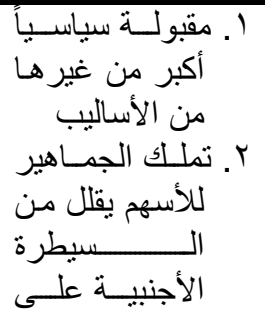 & 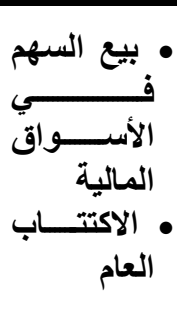 \\
\hline
\end{tabular}




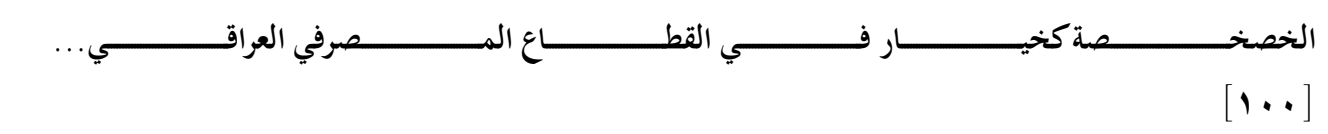

\begin{tabular}{|c|c|c|c|c|}
\hline أسباب الاخلوبتيار & الأهداف & السلبيات & الإيجابيات & الأسلوب \\
\hline & المساهمين & 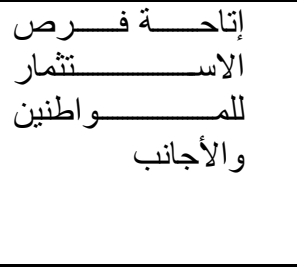 & 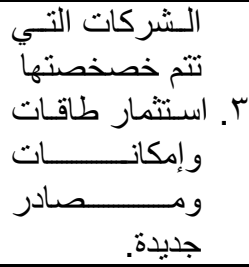 & \\
\hline 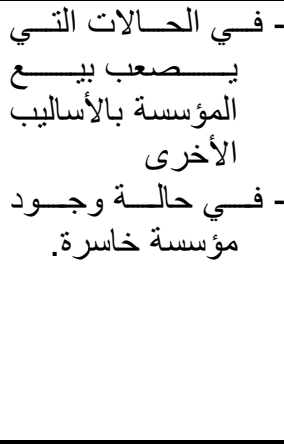 & 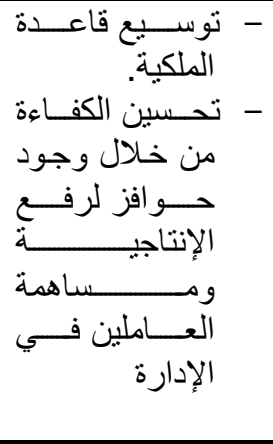 & 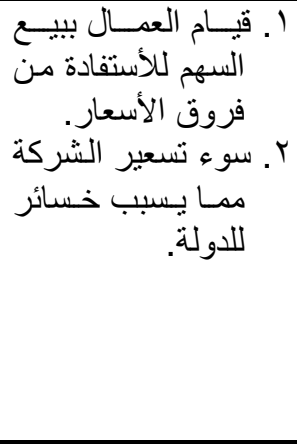 & 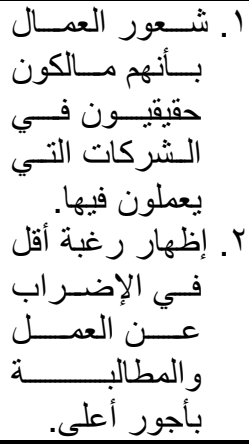 & والإلعاملين \\
\hline ـ عـدم المقـدرة الماليــة & 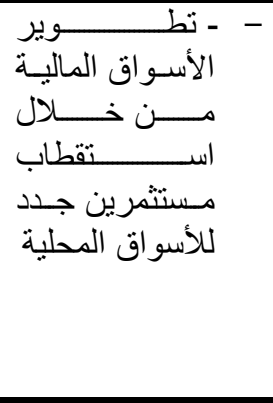 & 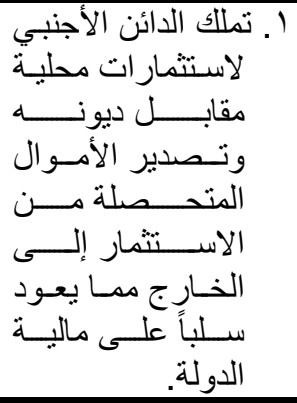 & 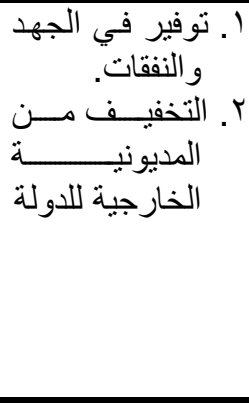 & مقايضة \\
\hline 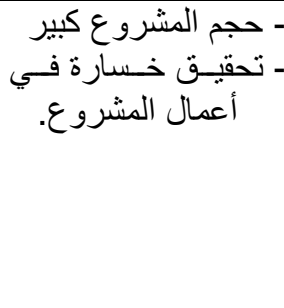 & 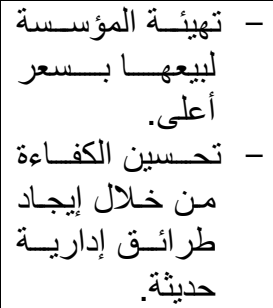 & 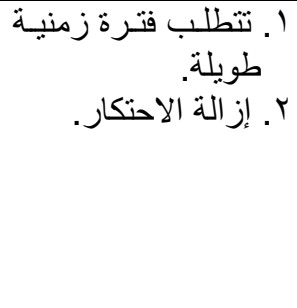 & 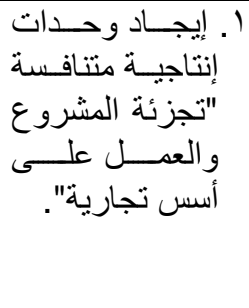 & إعادة الهويكلة \\
\hline
\end{tabular}

المصدر: رفعت عبدالحليم الفاعوري، ؟ . . ب، تجارب عربيـة في الخصخصة، المنظمـة العربيـة

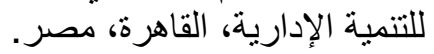

\section{رابعاً. أثر الخصخصة على الصناعة المصرفية}

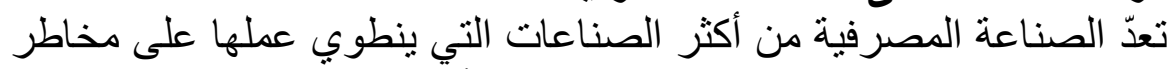

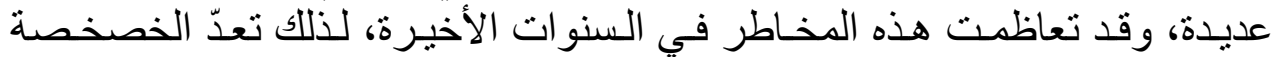

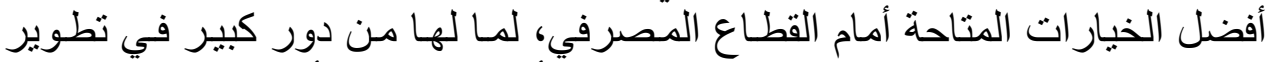
هذه الصناعة وتوسيعها، فهي تسعى إلى تحقيق أهداف عديدة الهيأ أهمها: 
1. زيادة المنافسة في السوق المصرفية

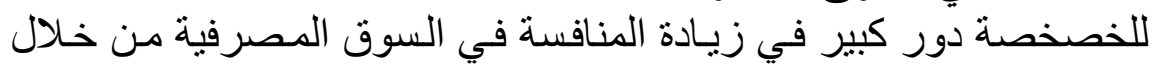

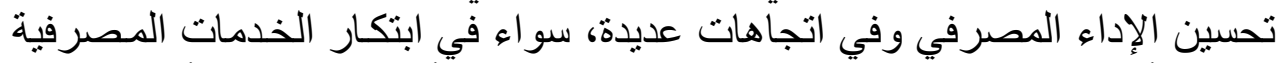

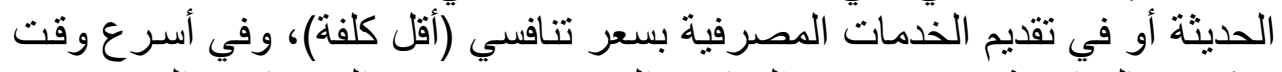

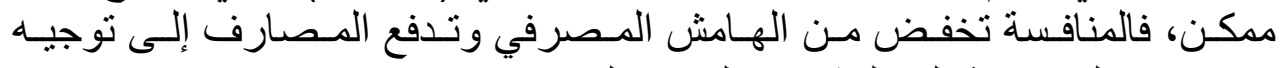

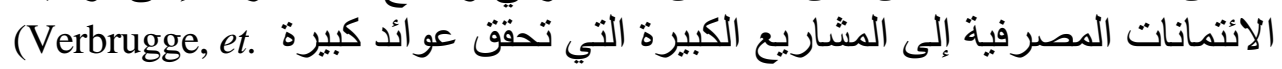

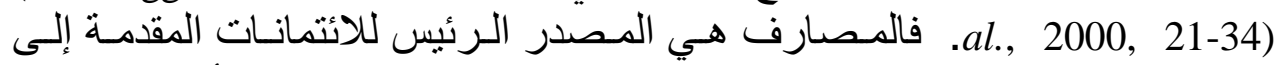

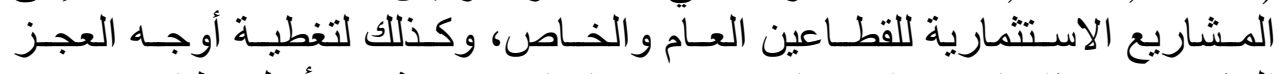

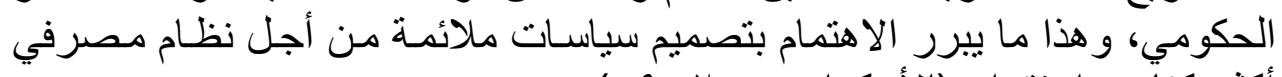

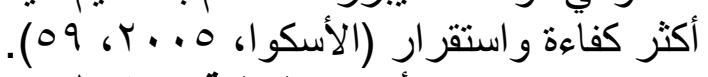

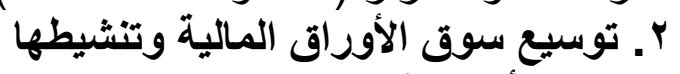

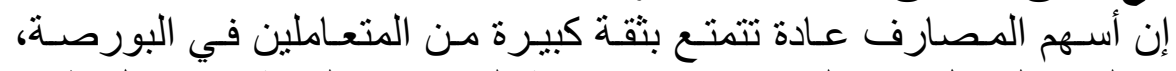

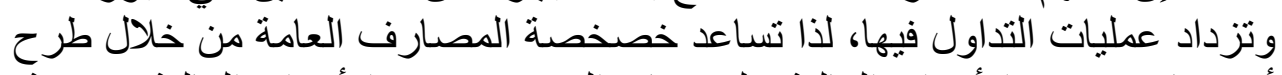

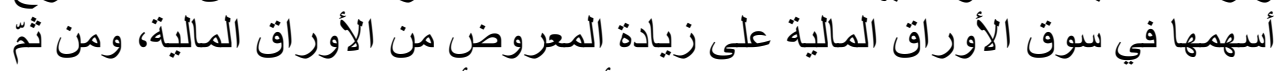

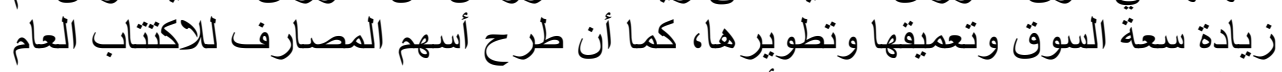

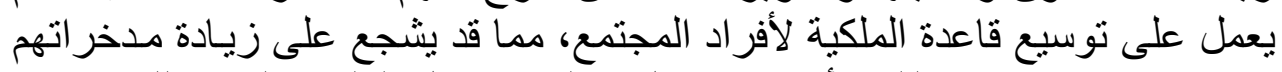

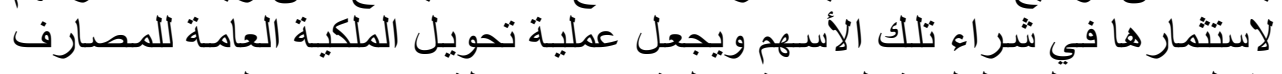

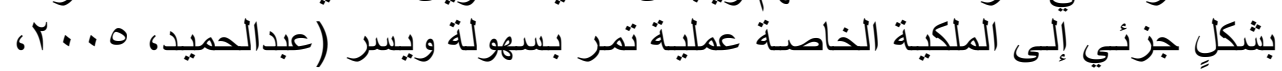

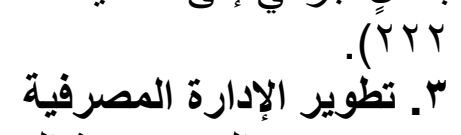

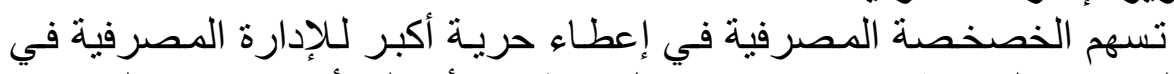

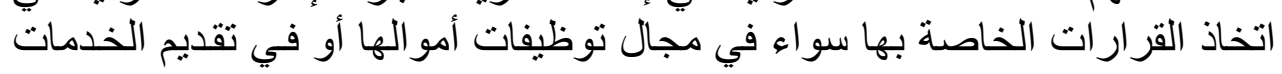

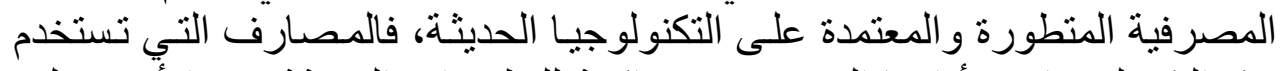

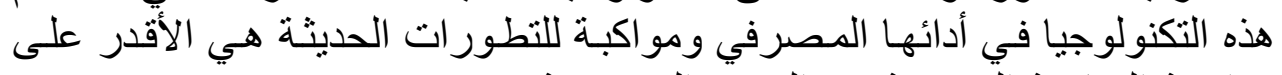

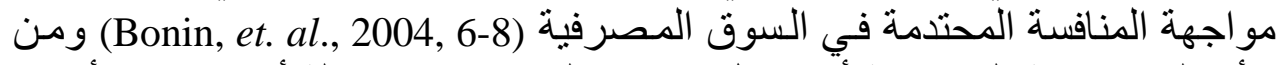

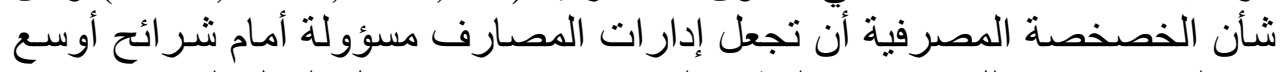

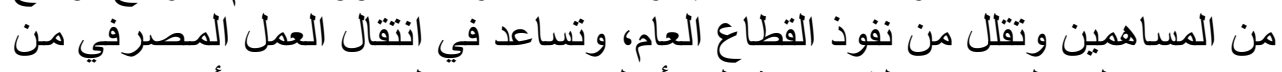

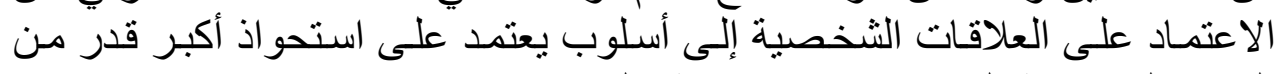

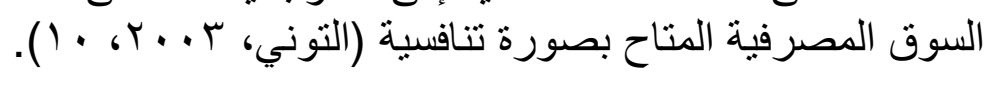

خامساً. الأسباب و الدوافع الرئيسة لخصخصة المصارف

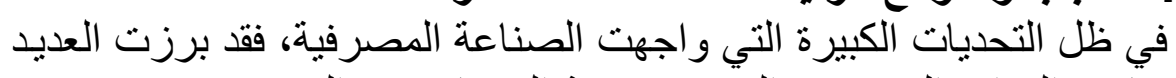

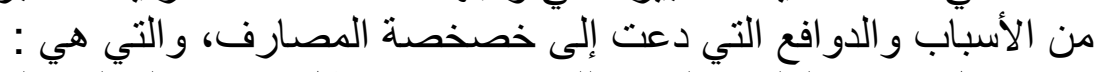

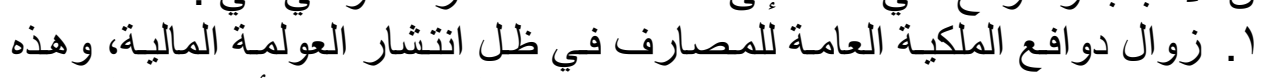

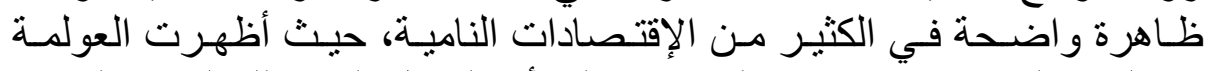

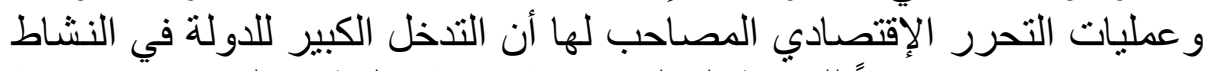

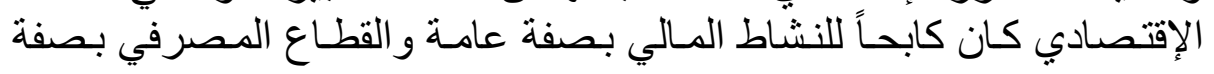




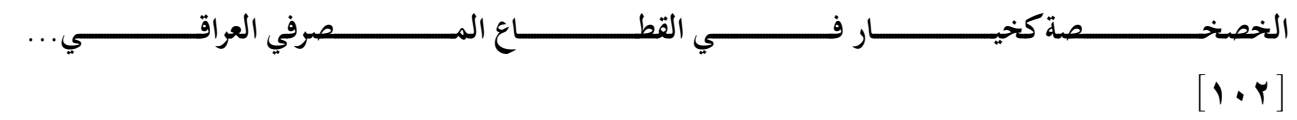

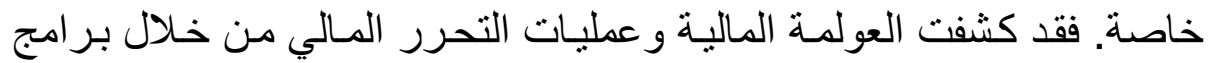

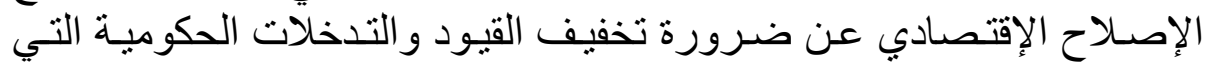

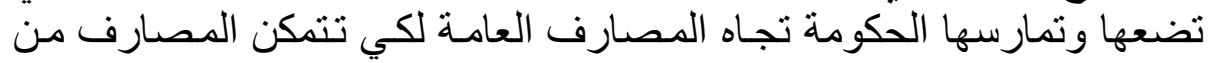

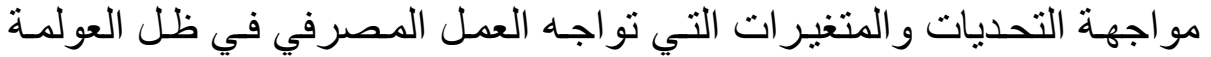
مثل: تغيير طبيعة النشاط المصرفي بعد تراجع أهمية الخدمات المصرفية التقليديـة

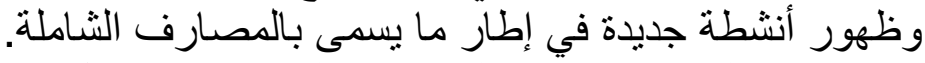

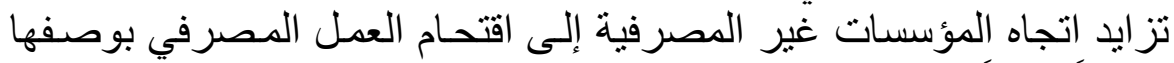

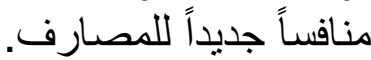

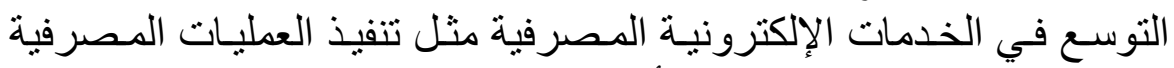

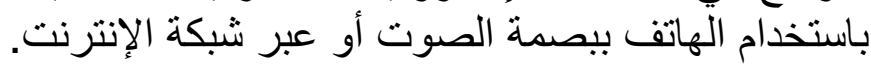

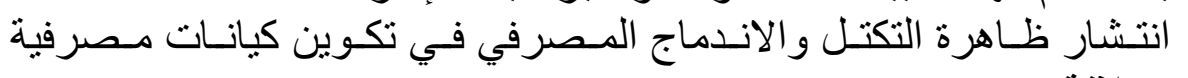
عملاقة.

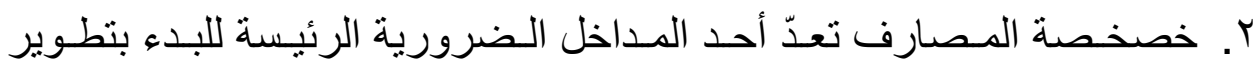

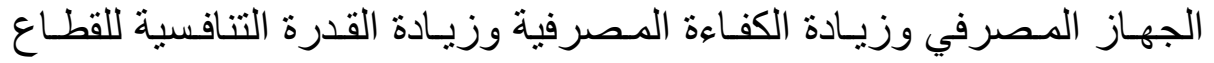

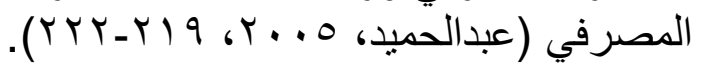

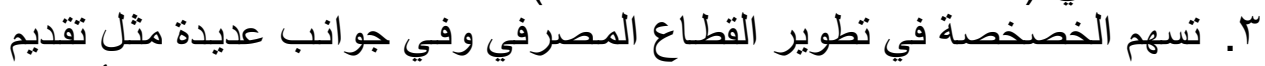

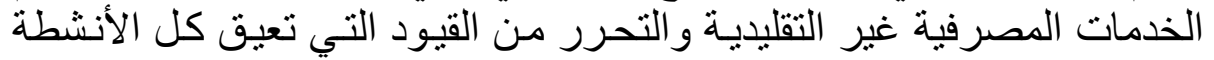

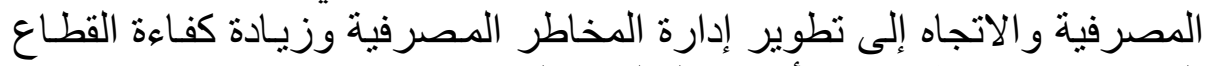

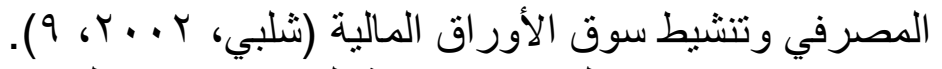

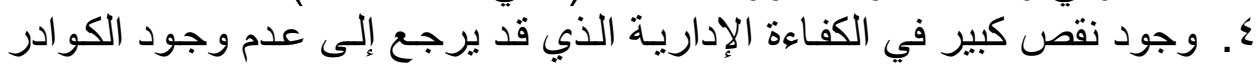

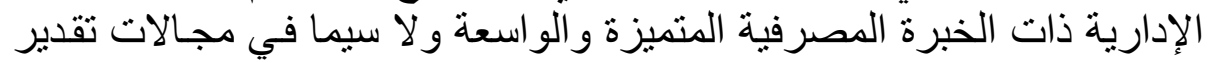
المخاطر و إدارة المحافظ الاستثمارية.

\section{كفاءة وفاعلية المصارف التجارية الحكومية العراقية وخيارات الخصخصة}

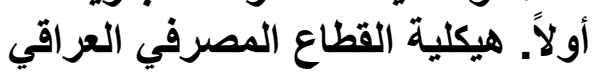
يتكون القطاع المصرفي العر أقي حالياً من مصرفين حكوميين هما الر افدين

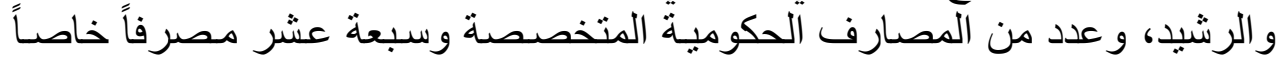

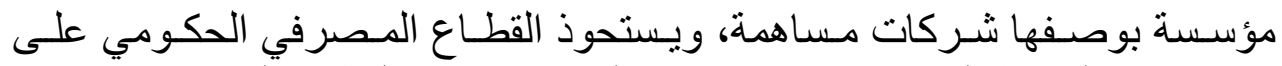

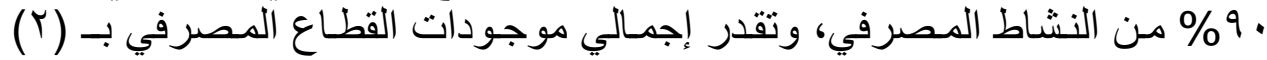

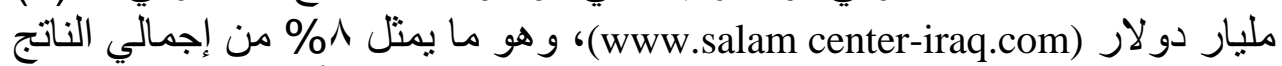

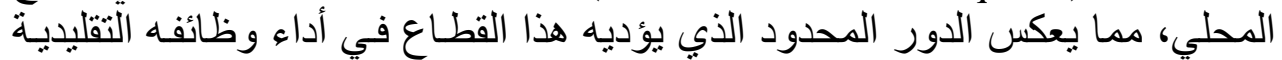

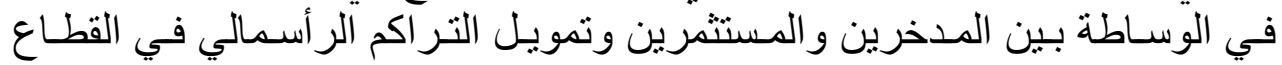
لم يؤدِ مصرفا الر افدين والرشيد أي دور رئبس في إقراض القطاع الإنتاجي الإي

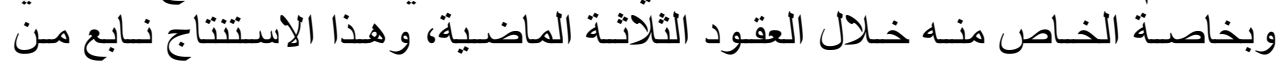




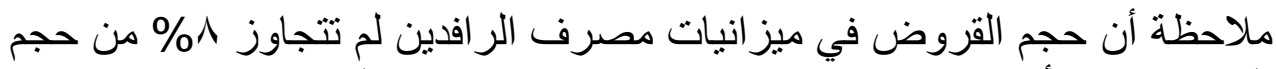

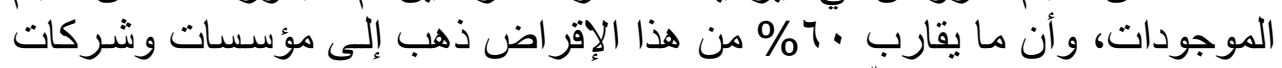

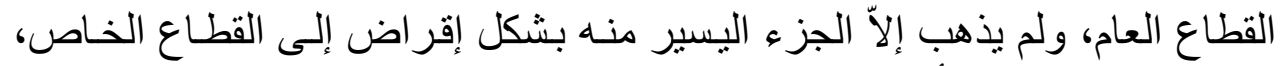

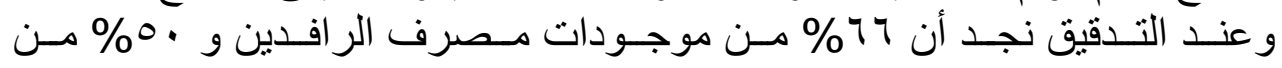

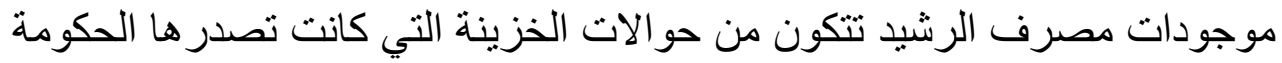

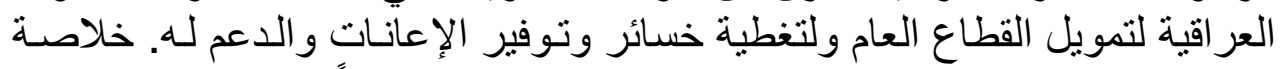

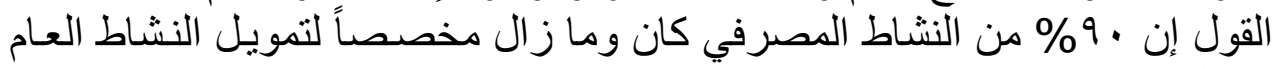

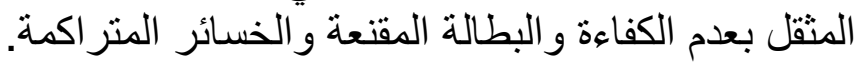

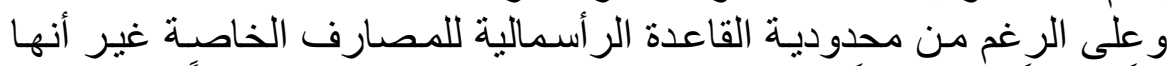

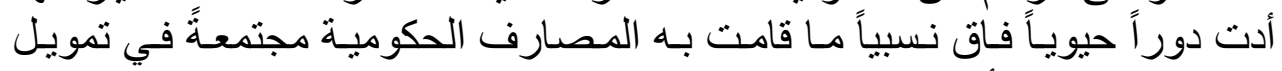

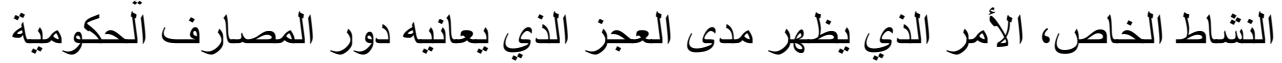

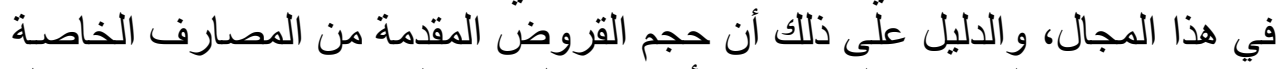

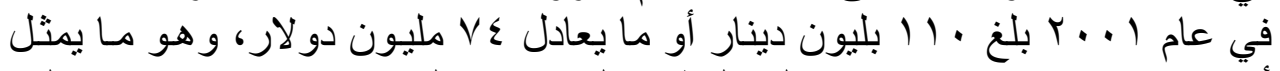

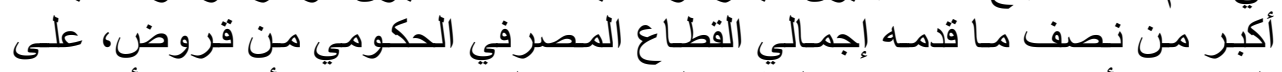

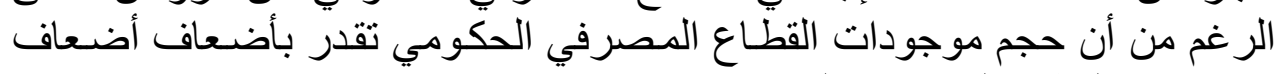
موجودات القطاع المصرفي الخاص.

ثثانياً. مؤثرات الكفاءة والفاعلية في المصارف التجارية العراقية

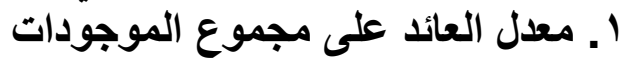

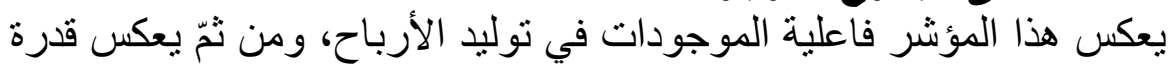

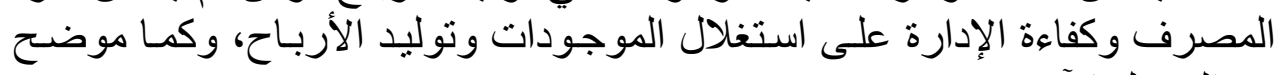

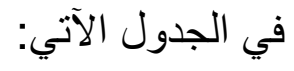

\begin{tabular}{|c|c|c|}
\hline \multicolumn{3}{|c|}{ 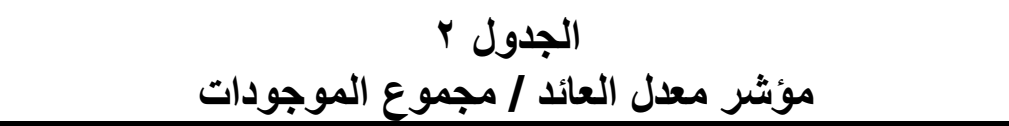 } \\
\hline مصرف الثرق الأوسط & مصرف الرافدين & المصرف \\
\hline$\because \cdot r$ & $\because \cdot r$ & $r \ldots$ \\
\hline$\because \cdot r$ & $\because \cdot 1$ & $r \ldots r$ \\
\hline$\because \cdot Y$ & $\because \cdot 1$ & $r \ldots r$ \\
\hline$\because .1$ & $\because \cdots 9$ & $r \ldots r$ \\
\hline$\cdot . \mu$ & $(\cdot \cdots \cdot r)$ & Y.. \\
\hline$\cdot . r$ & $\because \ldots r$ & $r \ldots o$ \\
\hline 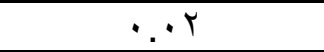 & $\because \cdots \Lambda$ & المتوسط \\
\hline
\end{tabular}




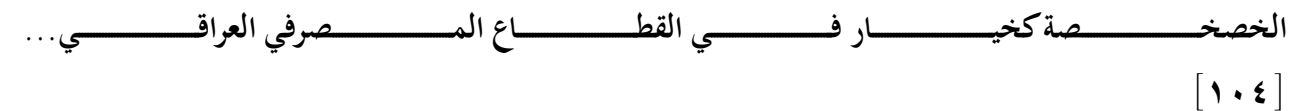

\begin{tabular}{|c|c|c|}
\hline مصرف الشرق الأوسط & مصرف الرافدين & المصرف \\
\hline$\because \cdots V$ & $\because \cdots V$ & الانحر اف المعياري \\
\hline
\end{tabular}

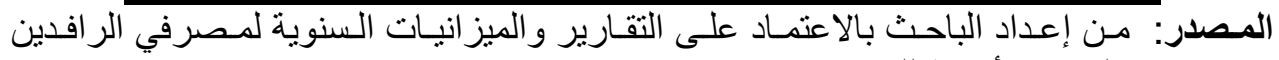

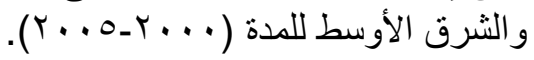

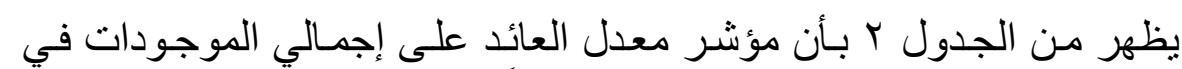

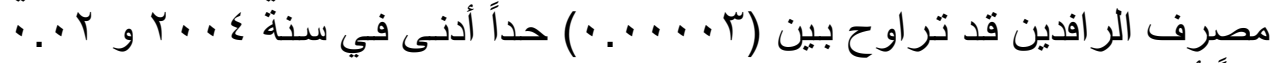

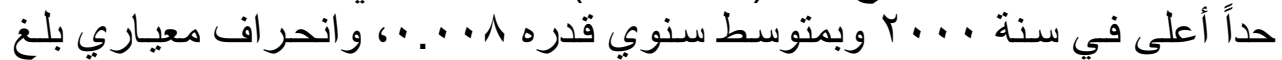

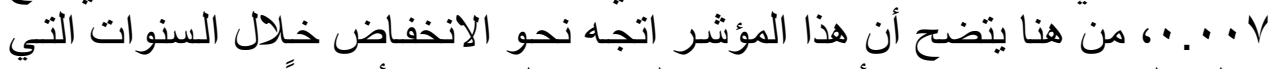

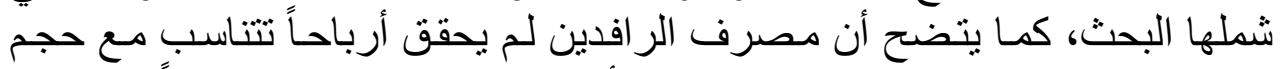

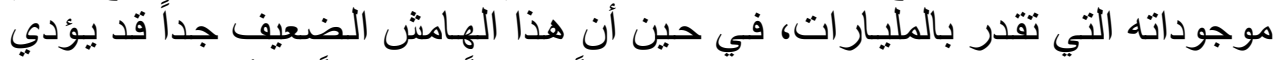

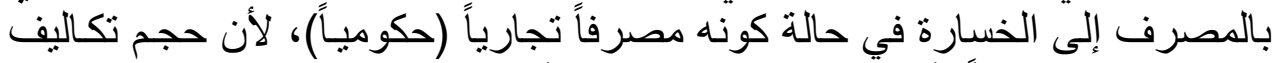

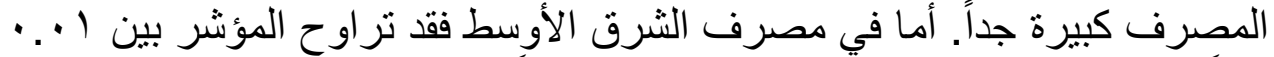

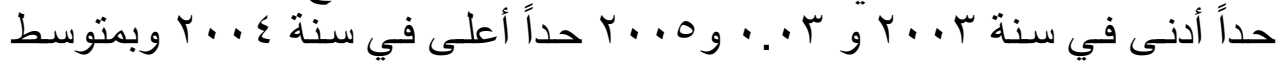

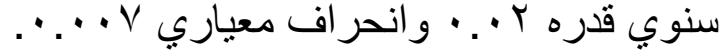
ץ ـ معدل العائد / الودائع يعكس هذا المؤشر قدرة الودر المصرف على توليد الأرباح من الودائع.

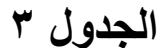

مؤشر معدل العائد / الودائع

\begin{tabular}{|c|c|c|}
\hline مصرف الثرق الأوسط & مصرف الرافين & المصرف \\
\hline$\cdot . \mu$ & $\because \cdot r$ & r... \\
\hline$\because \cdot r$ & $\because \cdot 1$ & $r \ldots 1$ \\
\hline$\because \cdot \varepsilon$ & $\because \cdot 1$ & $r \ldots r$ \\
\hline$\because \cdot Y$ & $\therefore 99$ & $r \ldots r$ \\
\hline$\cdot . r$ & $(\cdot \cdots 7)$ & $r \ldots \varepsilon$ \\
\hline$\because \varepsilon$ & $\because \ldots 7$ & $r \ldots o$ \\
\hline..$\mu$ & $\because \cdots 9$ & المتوسط \\
\hline.$\cdots v$ & $\therefore \cdots$ & الانحر اف المعياري \\
\hline
\end{tabular}

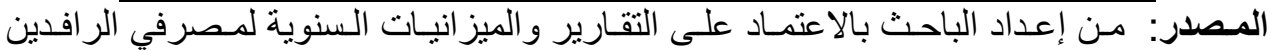

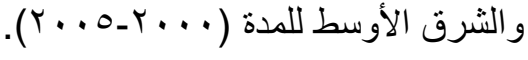




\section{النعيمي [1.0}

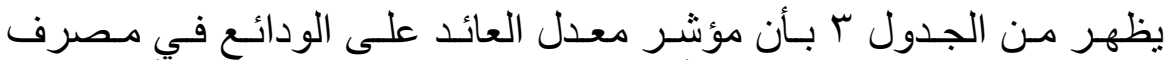

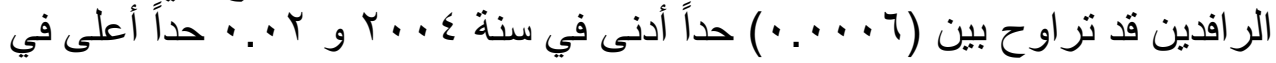

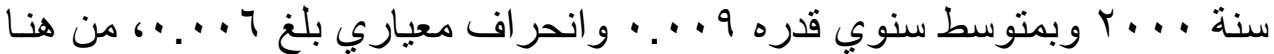

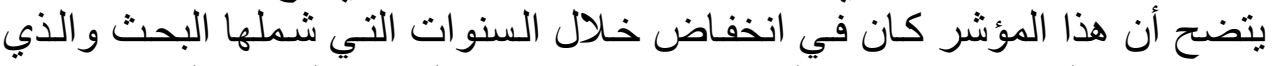

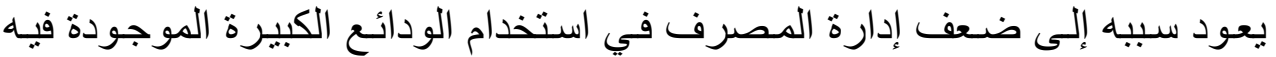

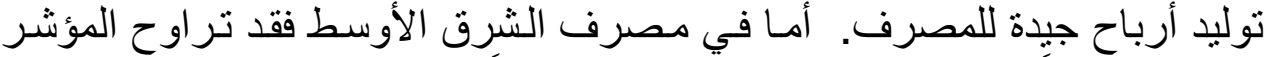

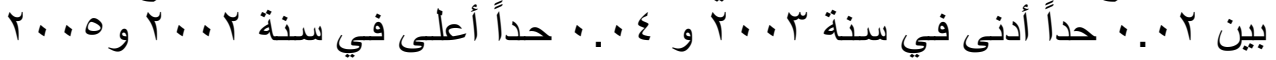

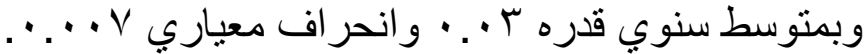

r. آق الملكية / إجمالي الموجودات

يشير هذا المؤشر إلى المدى الذي ذهب إلى إليه المصرف في الاعتماد على حق

الملكية في تمويل الموجودات.

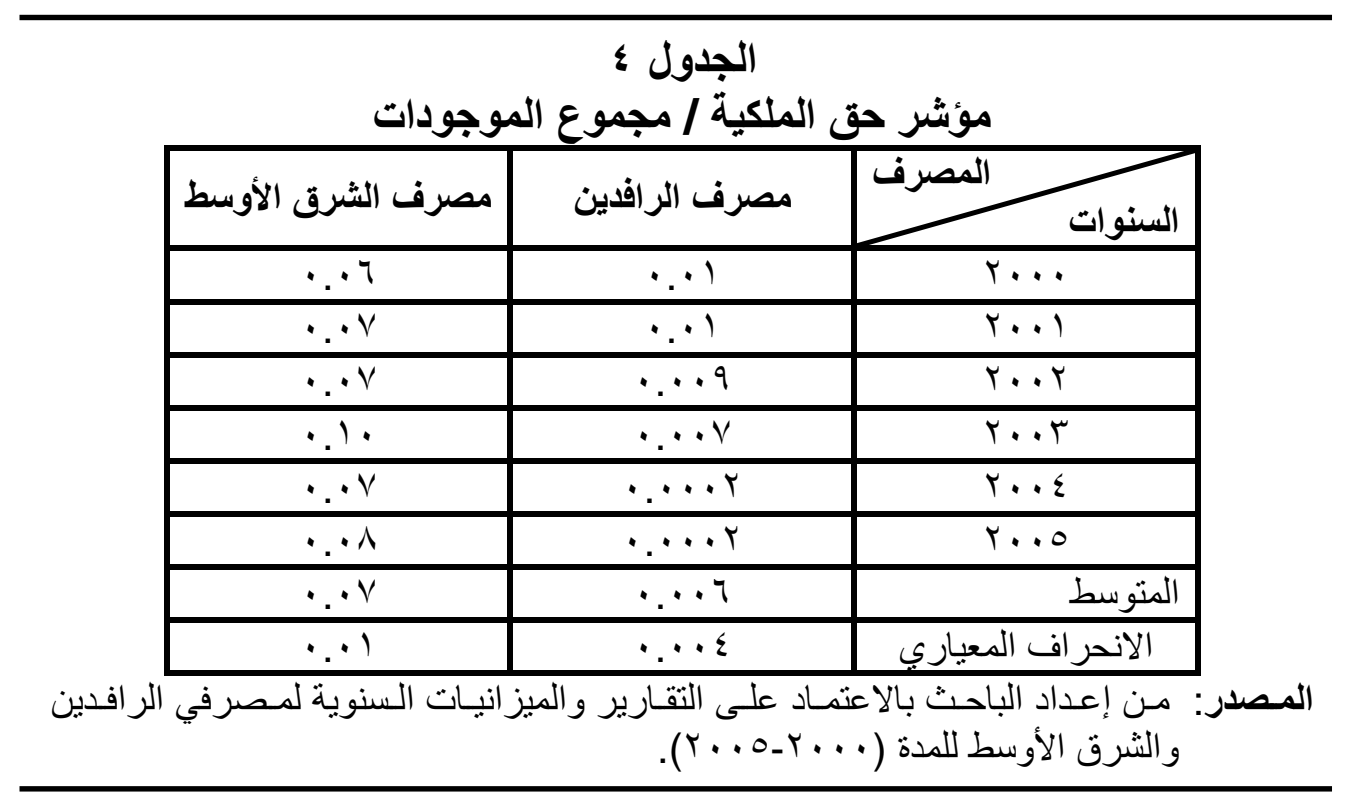

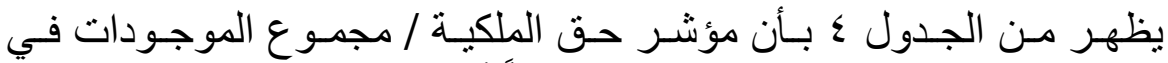

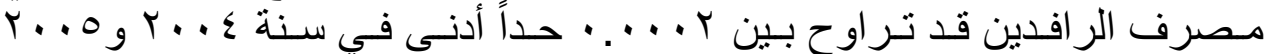

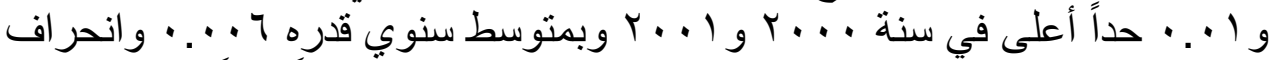

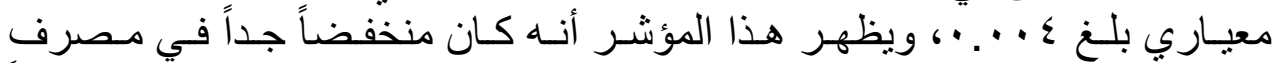

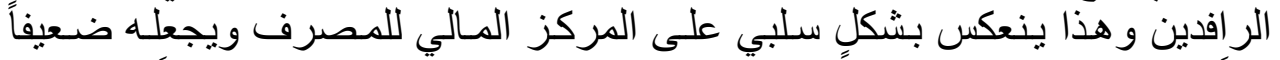

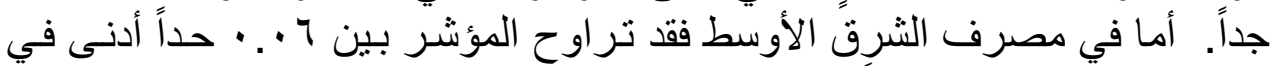

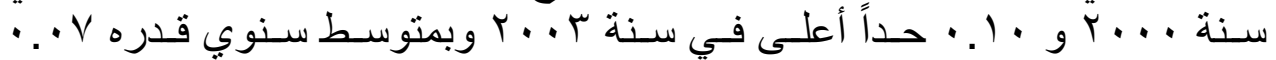

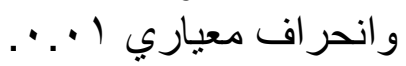

؛ ـ الائتمان النقي / إجمالي الموجودات 


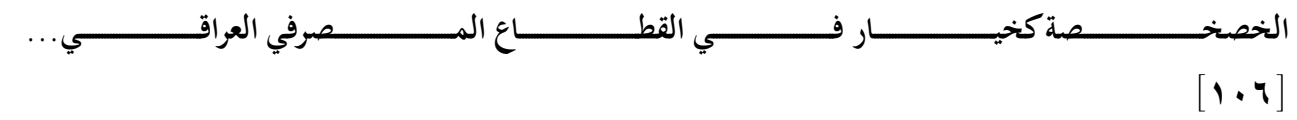

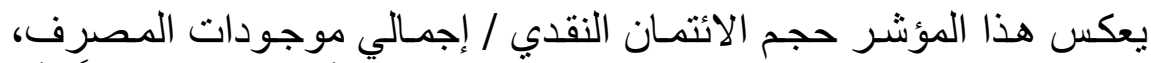

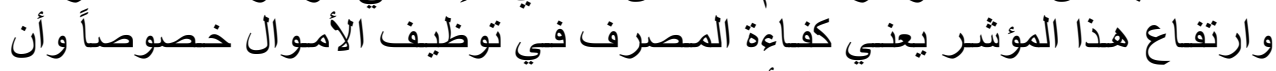

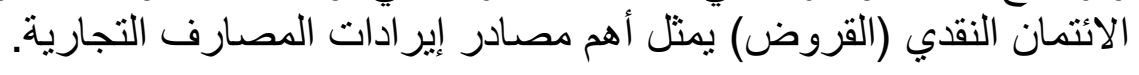

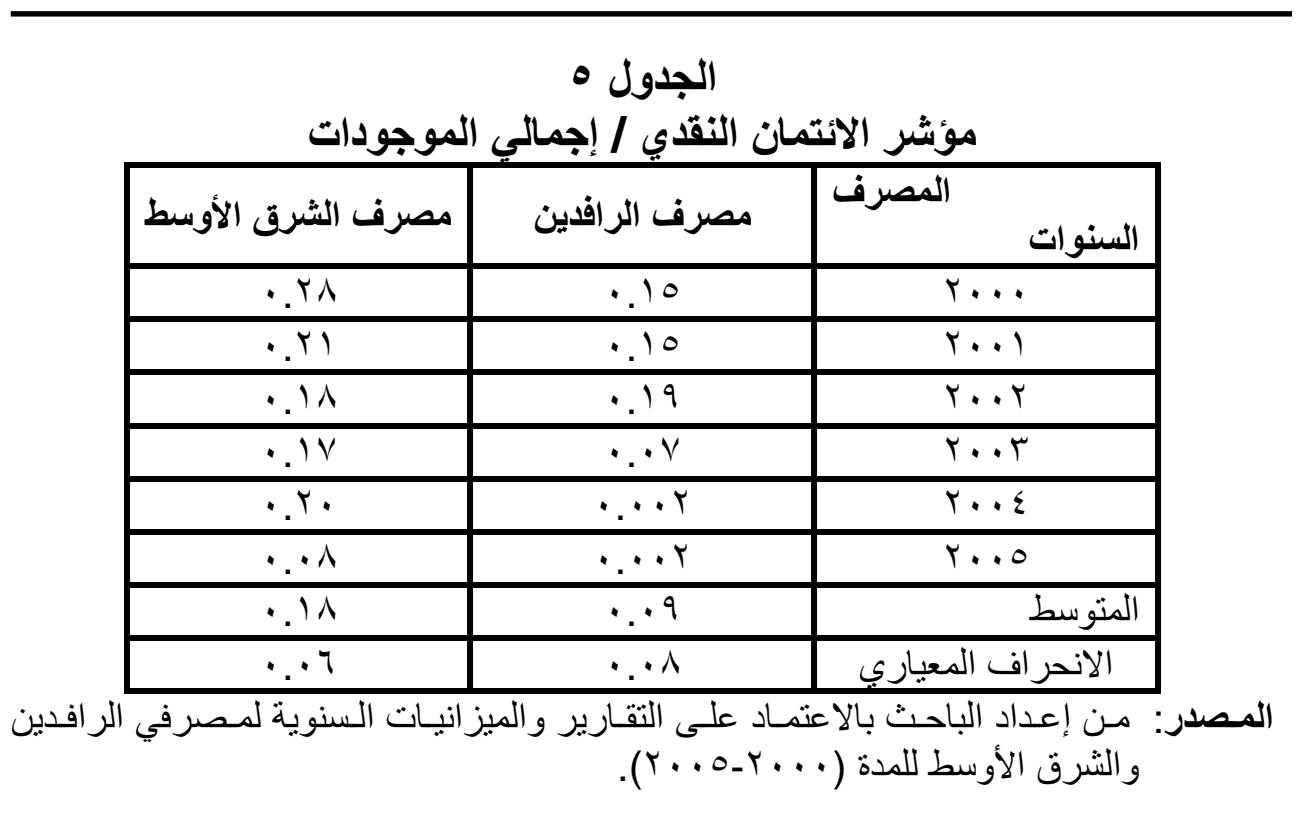

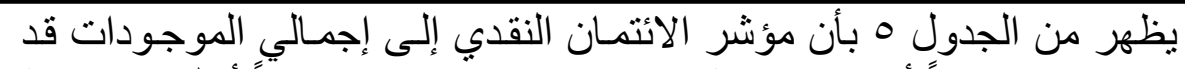

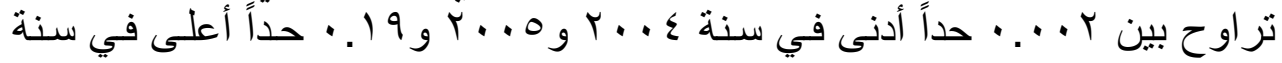

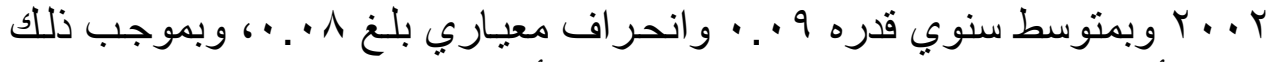

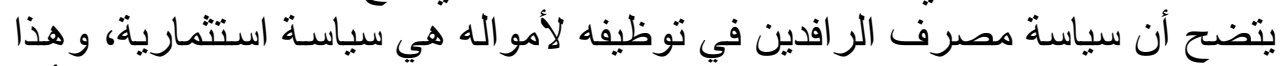

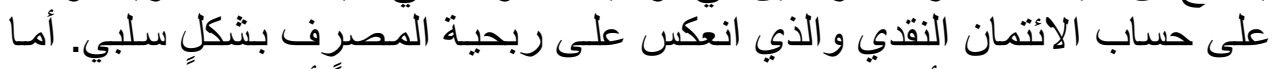

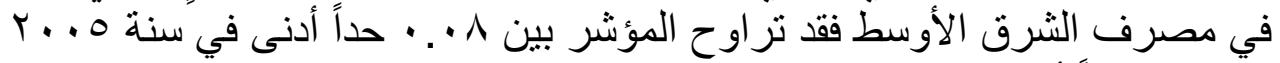

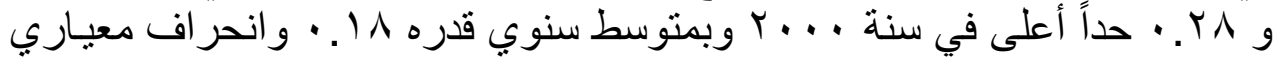
$\therefore \cdot 7$

مما سبق، يتضح أن إدارة مصرف الر افدين لم تكن كفوءة في إدارتهـ بشكلٍ

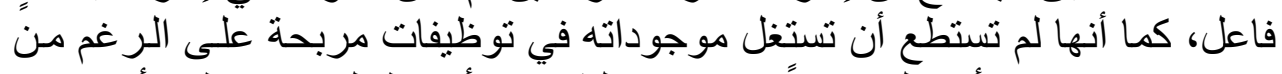

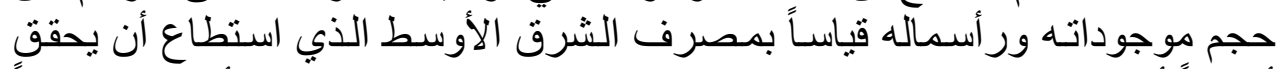

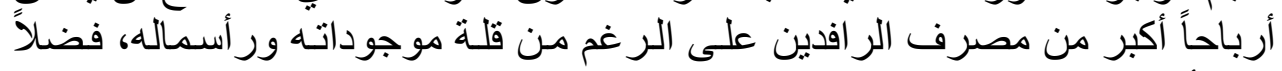

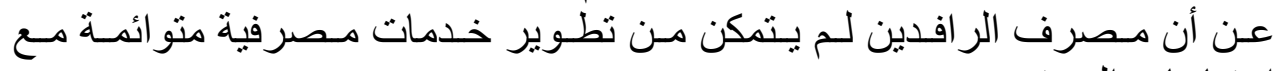

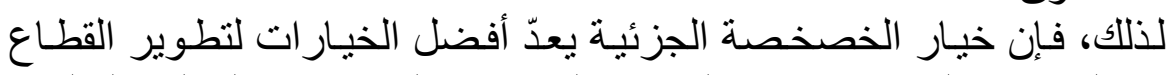
احتباجات السوق. المصرفي الحكومي العر اقي وزيادة القدرات التنافسية والتكييف مع العولمة المالية. 


\section{ثالثاً. خيارات الخصخصة في المصارف العراقية

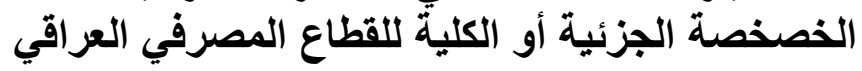

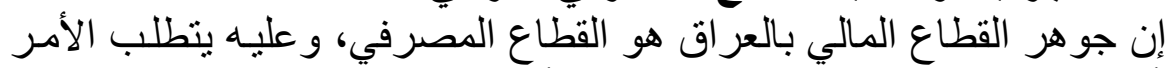

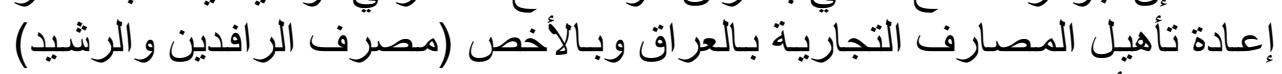

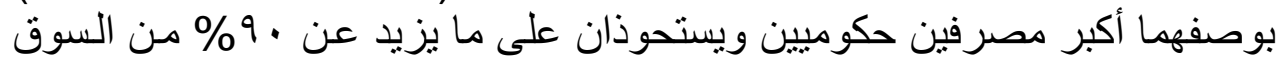

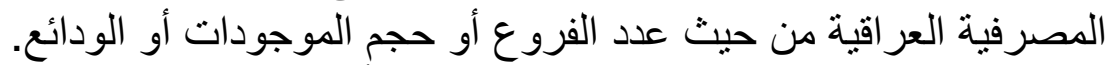

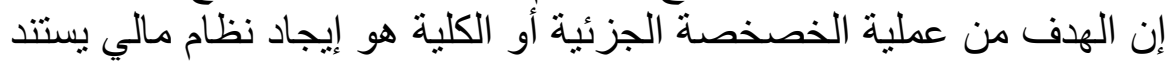

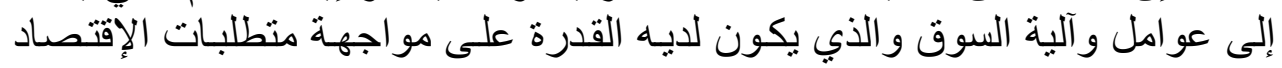

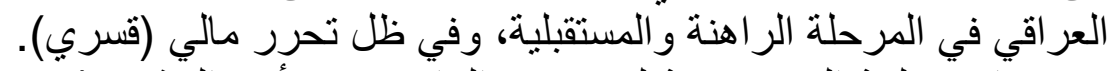

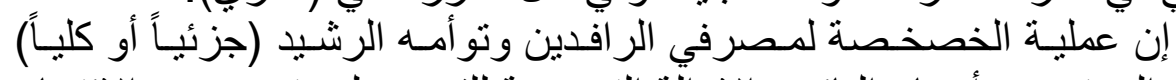

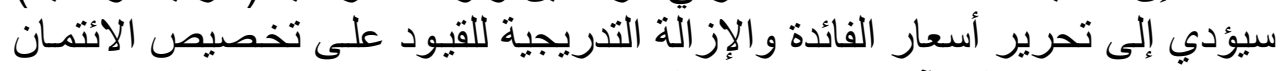

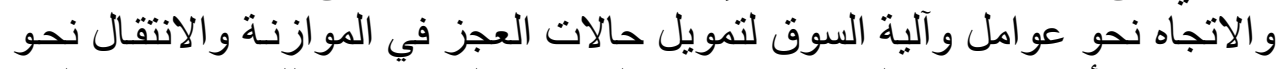

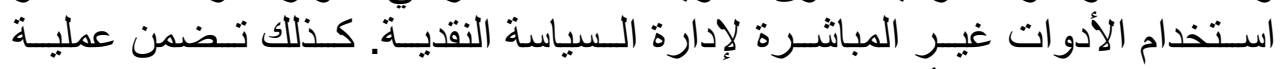

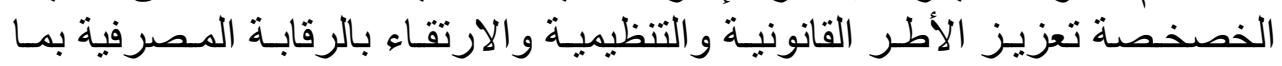

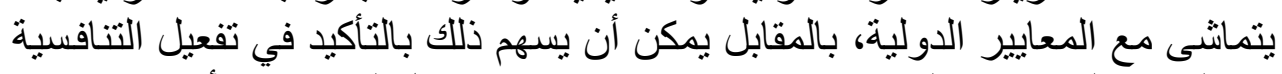

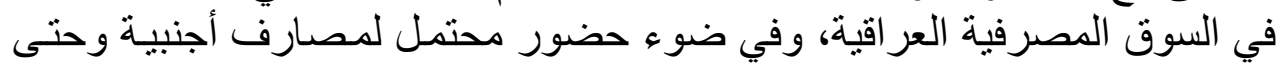

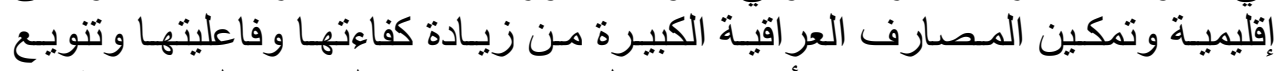

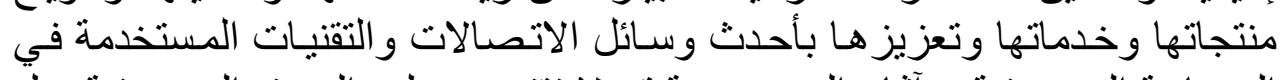

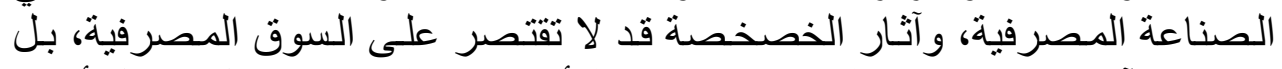

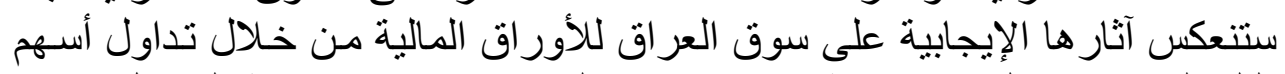

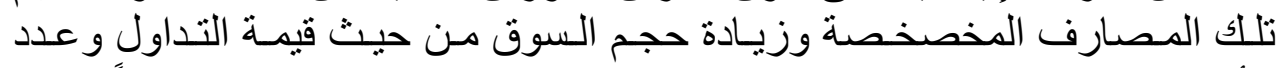

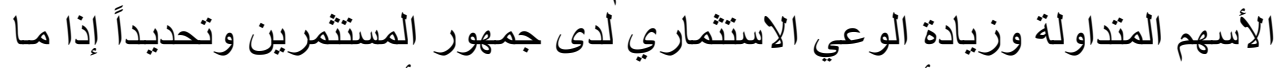

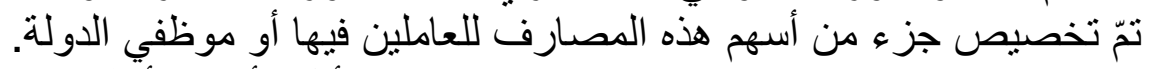

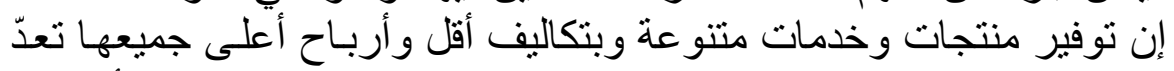

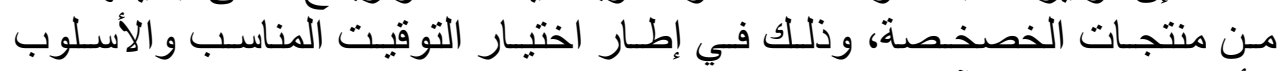
الأفضل في تجنب الآثار السلبية التي قد تنجم عن تللك العملية.

الاستنتاجات و المقترحات

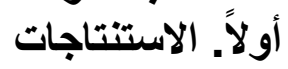

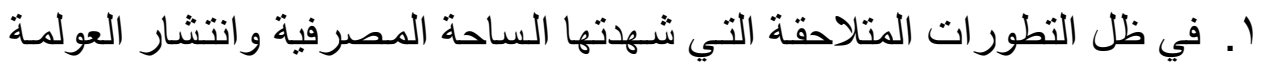

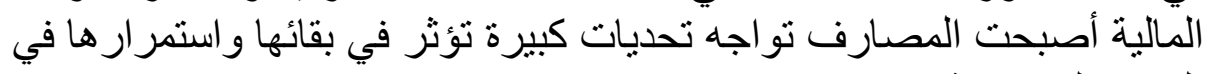

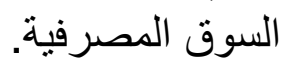

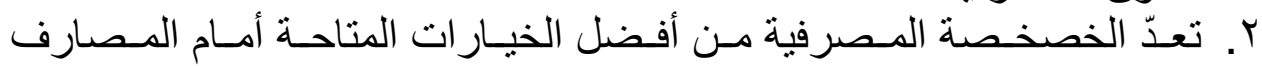

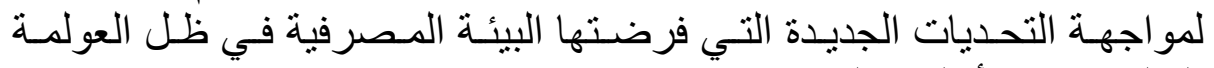

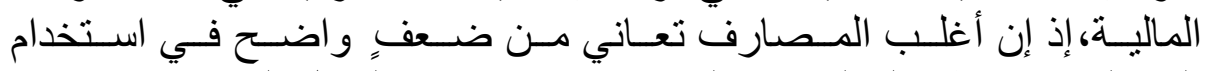

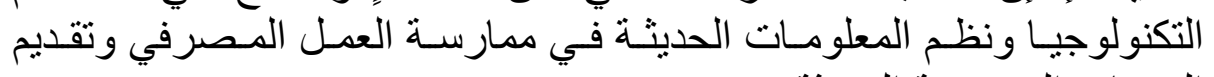

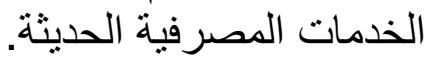




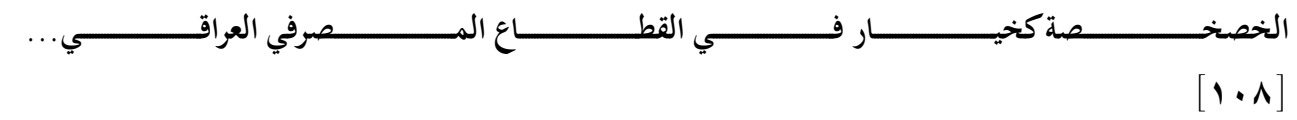

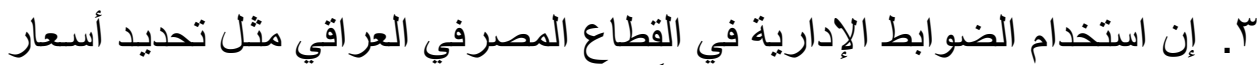

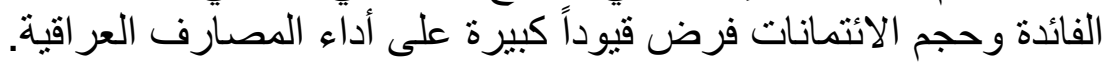

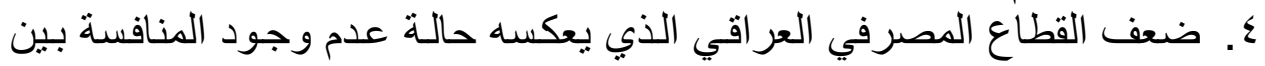

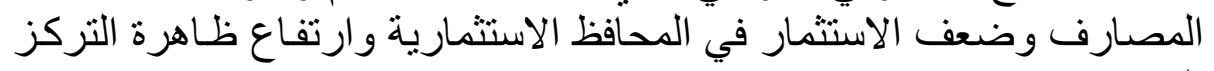

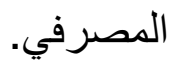

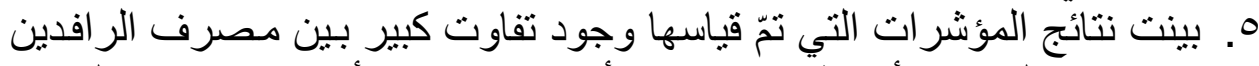

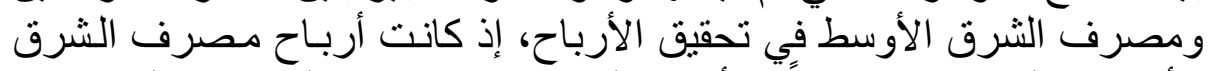

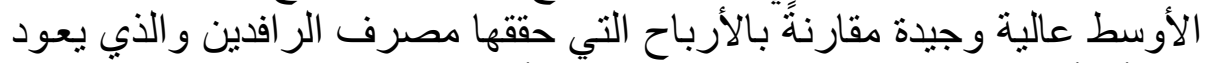

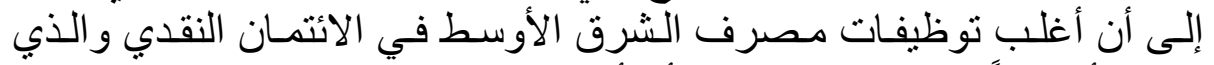

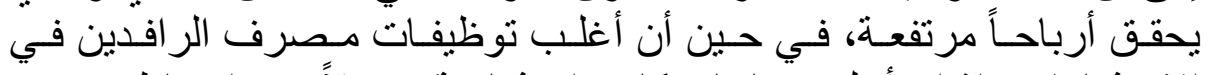

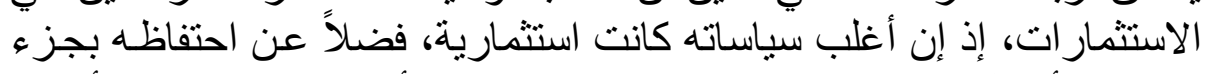
كبير من أمو اله كسيولة نقدية من دون توظيف، مما أدى إلى انخفاض النها الأرباح

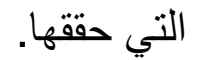

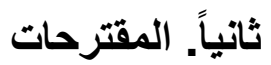

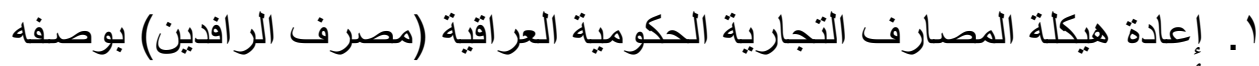

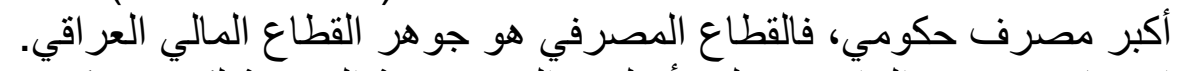

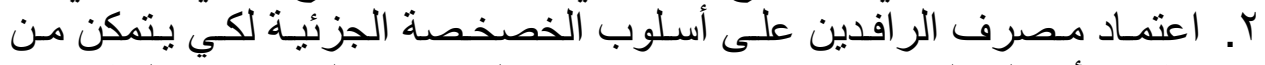

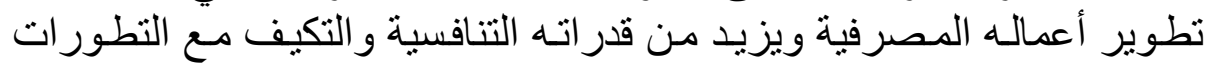

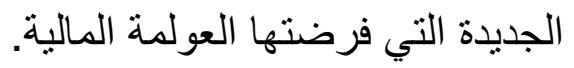

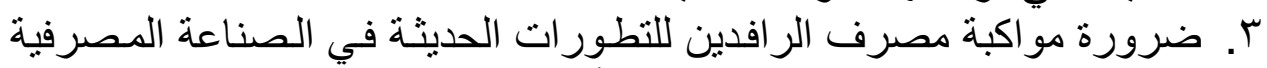

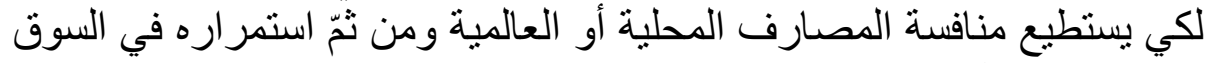

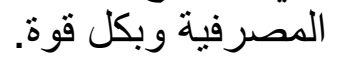

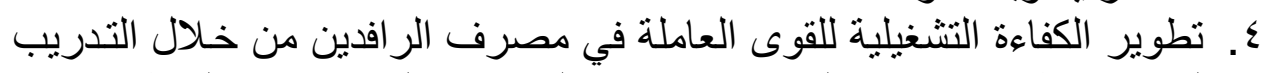

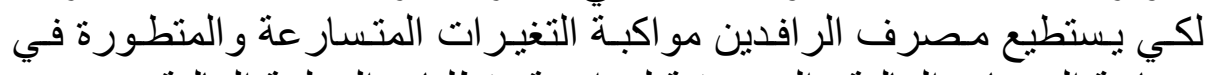

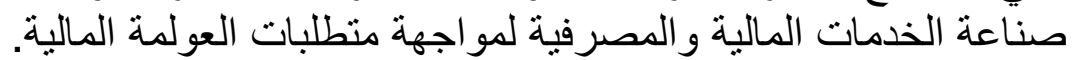

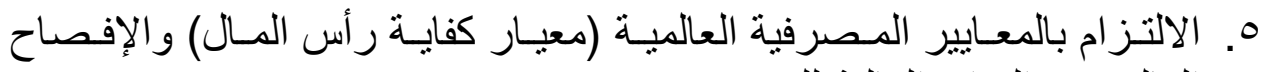

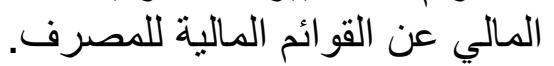

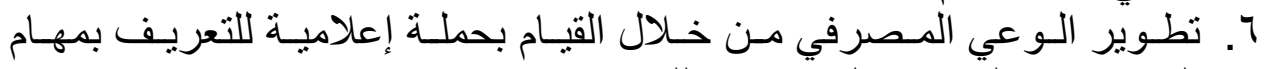
المصارف و الخدمات التي تقدمها للجمهور.

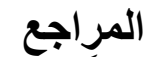

$$
\begin{aligned}
& \text { أولاً. المراجع باللغة العربية }
\end{aligned}
$$

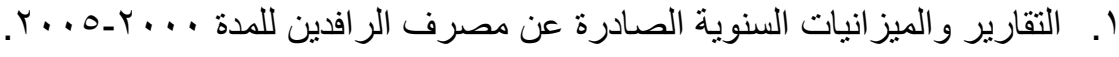




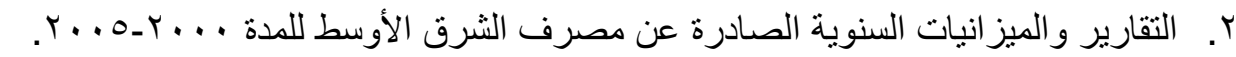

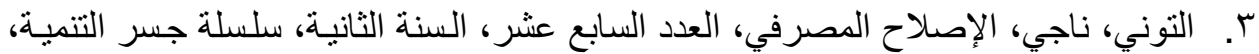

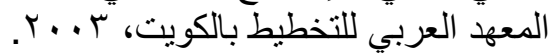

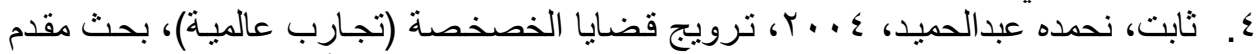

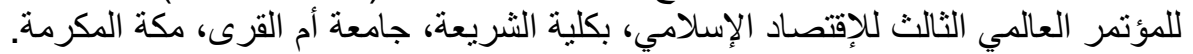

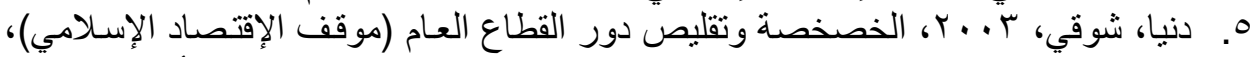

بحث مقدم للمؤتمر العالمي الثالث للإقتصاد الإسلامي، بكلية الثريعة، جامعة أم القرى، مكة الإنة

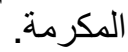

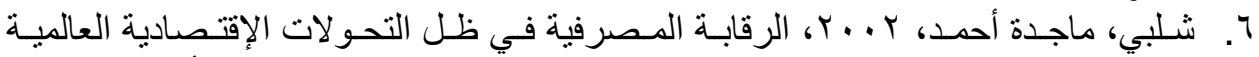

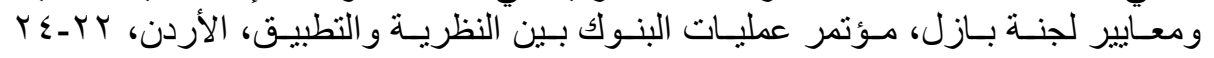

ديسمبر.

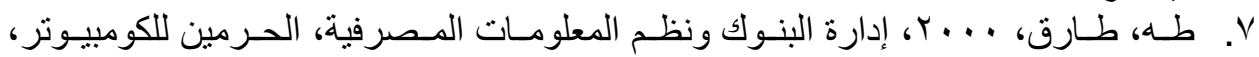

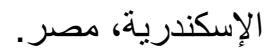

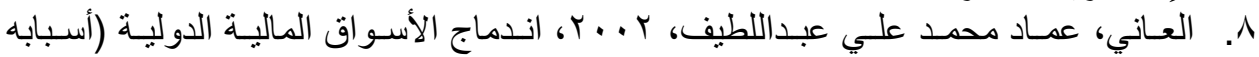

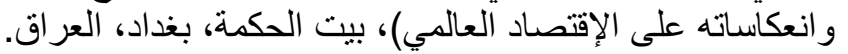

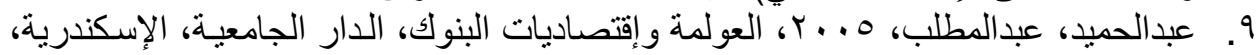

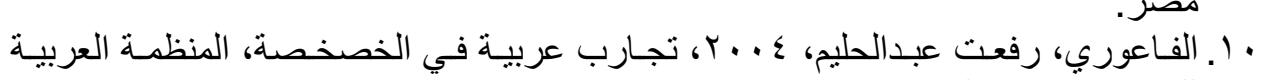

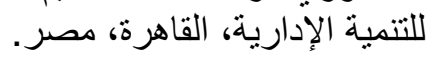

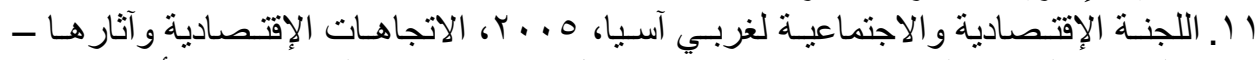

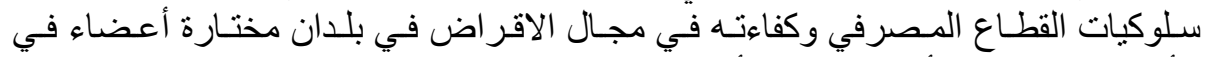

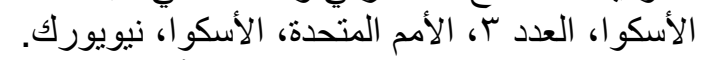

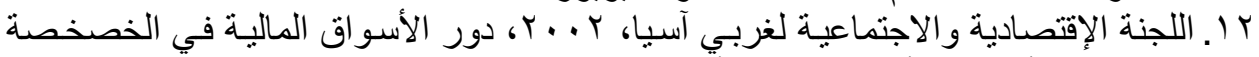

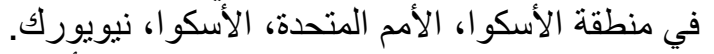

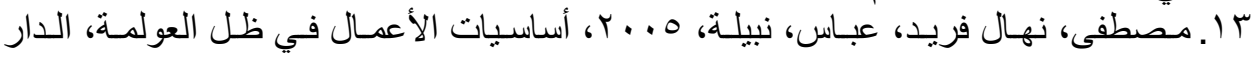

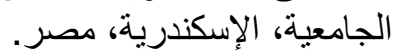

ثانياًٍ . المراجع باللغة الأجنبية

1. Allen N. berger, Robert Deyoung, Hesna Genay, Gregery F. Udell, 2000, "Globalization of Financial Institutions: Evidence from Gross-Border Banking Performance", Brookings Wharton Papers on Financial Services, Vol. (3).

2. George Clarke, 2000, Robert Cull, Getting to Yes Privatizing Banks Argentine World Bank, Washington D. C..

3. Iftekhar Hasan, K. Marton, "Banking in Transition Economy: Hungarian Evidence", Journal of Banking and Finance, 2003.

4. James Verbrugge Wanda Owen, William Megginson, 2000, "State Ownership and the Financial Performance of Privatized Bank: An Empirical Analysis Conference Proceeding of a Policy Research Work shop Held at the World Bank, March.

5. Jennifer S. Crystal, B. Gerard Dages, Lindas Goldberg, 2001, "Does Foreign Ownership Contribute to Sounder Banks, The Latin American Experience" in Litan, Robert E. Masson Paul and Pomerleano Michael eds Opendoors Foreign Participation in Financial Systems in Developing Countries Brooking Institutions Press, (Washington D. C.). 


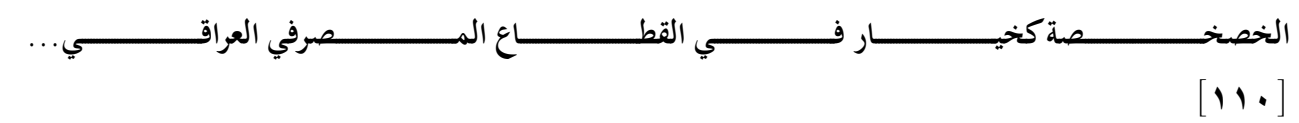

6. John P. Bonin, Iftekhar Hasan Paul Wachtel, 2003, Banks Performance Efficiency and Ownership in Transition Countries Paper Presented at the Ninth Dubrovnik Economic, Conference Sponsored by the Bank of Groatio, June.

7. John P. Bonin, Iftekhar Hasan Paul Wahtel, 2004, Privatization Matters: Bank Efficiencies in Transition Countries, World Bank Conference on Bank Privatization, Washington, D.C., November.

8. Rafael Laporta, Florencio Lopez-De-Silanes Audrei Shleifer, 2002, "Government Ownership of Bank, Journal of Finance.

9. Steven Fries, Anita Taci, 2003, "Cost Efficiency of Banks transition: Evidence from 289 Bank in 15 Post Communist Countries Paper Presented at the Ninth Dubrovnik Economic Conference Sponsored by the Bank of Croatia, June.

10. Steven Fries, Damien Neven, Paul Seabright, 2002, "Bank Performance in Transition Economics".

11. Stijn Classens, Asli Demirguc-Kunt Harry Huizinga, 2001, "How Does Foreign Entry Affect the Domestic Banking Market", Journal of Banking and Finance.

$$
\text { 1 أثأُ الانترنت }
$$

http://www. Salamcenter-iraq.com/economy12-hth. 